Max-Planck-Institut für demografische Forschung

Max Planck Institute for Demographic Research

Konrad-Zuse-Strasse 1 · D-18057 Rostock · GERMANY

Tel +49 (0) 3812081 - 0; Fax +49 (0) 3812081 - 202;

http://www.demogr.mpg.de

MPIDR WORKING PAPER WP 2012-014

FEBRUARY 2012 (REVISED APRIL 2013)

\title{
New Cohort Fertility Forecasts for the Developed World
}

Mikko Myrskylä (myrskyla@demogr.mpg.de)

Joshua R. Goldstein (goldstein@demogr.mpg.de)

Yen-Hsin Alice Cheng (cheng928@gate.sinica.edu.tw)

(C) Copyright is held by the authors.

Working papers of the Max Planck Institute for Demographic Research receive only limited review. Views or opinions expressed in working papers are attributable to the authors and do not necessarily reflect those of the Institute. 


\title{
New Cohort Fertility Forecasts for the Developed World
}

\author{
Mikko Myrskylä [1] \\ Joshua R. Goldstein [2] \\ Yen-Hsin Alice Cheng [3]
}

\begin{abstract}
The 1970s worries of the "population bomb" were replaced in the 1990s with concerns of population aging driven by falling birth rates. Across the developed world, the nearly universallyused fertility indicator, the period total fertility rate, fell well below two children per woman. However, declines in period fertility have largely been an artifact of later - but not necessarily less - childbearing. We produce new estimates of the actual number of children women have over their lifetimes - cohort fertility - for 37 developed countries. Our results suggest that family size has remained high in many "low fertility" countries. For example, cohort fertility averages 1.8 for the 1975 birth cohort in the 37 countries for which average period total fertility rate was only 1.5 in 2000. Moreover, we find that the long-term decline in cohort fertility has flattened or reversed in all world regions previously characterized by low fertility. These results are robust to statistical forecast uncertainty and the impact of the late 2000s recession. An application of the new forecasts analyzing the determinants of cohort fertility finds that the key dimensions of development that have been hypothesized to be important for fertility - general socioeconomic development, per capita income, and gender equality - are all positively correlated with fertility for the 1970s cohorts. Gender equality, however, emerges as the strongest determinant: where the gap in economic, political, and educational achievement between women and men is small, cohort fertility is high, whereas where the gap is large, fertility is low. Our new cohort fertility forecasts that document the flattening and even reversal of cohort fertility have large implications for the future of population aging and growth, particularly over the long term.
\end{abstract}

[1] Corresponding author. Max Planck Institute for Demographic Research, Konrad-Zuse-Str 1, 18057 Rostock, Germany. Email myrskyla@demogr.mpg.de. Phone: 49 (0)381 2081-118, Fax: 49 (0)381 2081-418

[2] Max Planck Institute for Demographic Research, Konrad-Zuse-Str 1, 18057 Rostock, Germany. Email goldstein@demogr.mpg.de. Phone: +49 (0)381 2081-107

[3] Institute of Sociology, Academia Sinica, 128, Sec. 2, Academia Road, Taipei 11529, Taiwan. Email cheng928@gate.sinica.edu.tw. Phone: + 886 (0)2 2652-5162 


\section{INTRODUCTION}

Public concern about the "population bomb" has in recent decades been replaced with fears of "empty cradles" and "demographic winter" (Ehrlich 1971; Longman 2004; Stout 2008). The key demographic concerns of the developed world - population aging, future health and pension burdens, replacement migration, and labor shortages - are all driven in some or large part by low fertility. The European Commission, for example, has identified fertility declines to levels of 1.5 children per woman, far below the replacement level of 2 children, to be among the key challenges for policy makers (European Commission 2005). Some scholars even worry of a "low fertility trap” of downward spiraling birth rates (Lutz, Skirbekk and Testa 2006). While period fertility has declined, the desired number of children has remained at or above two (Bongaarts 2001; Goldstein, Lutz and Rita Testa 2003), stirring concerns about unhappy citizens not being able to reach their childbearing goals (European Commission 2006; OECD 2007).

\section{FIGURE 1 ABOUT HERE}

These concerns are based on trends in the almost-universally used fertility indicator, the period total fertility rate (TFR). As shown in Figure 1, average period TFR in six world regions (37 countries) dropped below 1.5 at the turn of the century. In Europe the average period TFR reached its low of 1.37 in 1999, and despite modest increases in the last years, in 2008 threequarters of Europe’s population still lived in countries with period TFR below 1.6. In East Asia period fertility is even lower, averaging 1.2 for Hong Kong, Korea, Japan and Singapore.

Demographers have long argued that the sharp declines in period fertility, experienced throughout the developed world, are a mix of a real decline in family size and an artefact of cross-sectional measurement when births are being delayed to older ages (Bongaarts 2001; 
Bongaarts and Feeney 1998; Ryder 1956). Postponement of fertility spreads the births that would have occurred in a single year across a larger span of time. Such postponement reduces the agespecific period fertility rates and attenuates the observed level of the period total fertility rate. On the other hand, when postponement of fertility comes to an end, the period total fertility rate may increase closer to what it had been if there had been no postponement. Indeed, some have interpreted the recent increases in period total fertility - for example, in Europe from the low 1.37 in 1999 to 1.56 in 2008 (Vienna Institute of Demography 2010) as being entirely driven by ending of the fertility postponement, without any increase in the quantum of fertility (Bongaarts and Sobotka 2011).

Due to the influence of the timing effect on period total fertility rate, it has been suggested that the period total fertility rate should be replaced by measures that adjust for the influence of birth timing (Sobotka and Lutz 2009). Such measures aim at recovering the true "quantum” of fertility that prevails net of the changes in the timing of births (Bongaarts and Feeney 1998; Bongaarts and Sobotka 2011; Kohler and Philipov 2001). Despite the adjustments, however, these do not describe the true fertility experience of any real cohort of women. An alternative to adjusting period measures of fertility is to analyze directly the lifetime fertility of women by their birth year. Such a measure, cohort fertility, has the straightforward and simple interpretation as the average number of children women who were born in a certain year have over their lifetimes.

Little, however, is known about trends in cohort fertility, potentially for two reasons. First, to measure cohort fertility for any birth cohort, one needs data over the whole reproductive period, which is typically defined to extend from age 15 to age 49. Second, to analyze cohort fertility for recent cohorts, for example those born in 1975 who are in 2011 aged 36 years, one needs to forecast the remaining fertility. The scattered existing literature suggests very low lifetime 
fertility for the 1970s cohorts - women who are now in their 30s and early 40s - in the developed world. In rich East Asian countries women born around 1970 are forecast to have on average less than 1.5 children (Frejka, Jones and Sardon 2010). Two thirds of the European population lived in 2008 in countries with cohort fertility considerably below replacement (Frejka and Sobotka 2008), and several countries (Italy, Spain, Austria, Germany, Switzerland) are predicted to have as low as 1.2-1.3 fertility for the 1975 cohort (Frejka and Sardon 2004). Across all western market-economies the average fertility for the 1975 birth cohort is predicted to be 1.6 (Frejka and Sardon 2004).

Here we provide a new outlook on the cohort fertility patterns around the globe using the most recent data and a simple new method for completing the fertility for cohorts who are currently in their 30s and early 40s. We analyze data from 37 countries covering all world regions with prolonged below-replacement period fertility. Our forecasts are based on a new method for estimating the completed childbearing of cohorts that are still in their 30s and 40s. The method allows the trend in age-specific fertility observed over the last 5 years to continue for another 5 years and avoids much of the systematic underestimation of previous research which predicted lifetime fertility for the 1975 cohorts to be as low as 1.2-1.3 children per woman in several European countries (Frejka and Sardon 2004).

Figure 1 shows the key result of our analysis, plotting the average cohort and period fertility among the 37 countries. This glimpse of the results shows that the decline in period fertility has been largely an artefact of later - not less - childbearing: while the period fertility declined below 1.5 in late 1990s-early 2000s, the average cohort fertility has remained on a much higher level and averages 1.8 children per woman for the 1975 birth cohort. In our detailed country- and regional analyses we further show that the long-term trend in fertility decline has flattened or 
reversed in all world regions previously characterised by low fertility. Our results have large implications for the future of population aging and growth, particularly over the long term.

We illustrate the usefulness and importance of the new cohort fertility forecasts with two applications. First, we analyze the long-term demographic implications of a fertility rate that is close to the newly estimated cohort fertility rate, against the counterfactual that fertility would stay at the levels recently observed in the period perspective. Second, we analyze the sociodemographic determinants of the national level differences in cohort fertility rates. Our results show that the key dimensions of socioeconomic development that previous research has hypothesized to be important determinants of fertility increases - the Human Development Index (Myrskylä, Kohler and Billari 2009), per capita Gross Domestic Product (Luci and Thévenon 2010), and gender equality (Feyrer, Sacerdote and Stern 2008; McDonald 2000) - are all positively correlated with cohort fertility levels. Gender equality, however, emerges as the strongest determinant of cohort fertility: where the gap in economic, political, and educational achievement between women and men is small, cohort fertility is high, whereas where the gap is large, cohort fertility is low. 


\section{DATA AND METHODS}

\section{Data}

Our analysis is based on data on period fertility rates by single year of age for 37 countries. We use fertility rates for ages 15-49, starting from year 1965. Thus the first cohorts we include in the analysis are those born in 1950. For the majority of the countries, the last observation is year 2009, implying that for cohorts born up to 1965 cohort fertility is almost completely observed (up to age 44), and for later born cohorts forecasting is needed. Our data sources are the Human Fertility Database (2012), Eurostat (2012), national statistical agencies, and individual researchers through personal communication. Table 1 lists the countries and the data sources.

\section{TABLE 1 ABOUT HERE}

As shown in Table 1, for some countries the data starts later than in 1965. For example for Australia, the data starts in year 1975. In such cases we have completed the past fertility history by backcasting the fertility rates to year 1965 by assuming that the rates that prevailed in the oldest observation year (in the case of Australia year 1975) had been constant since 1965. This results in a conservative estimate for the cohort fertility: in most countries in which we had to use backcasting, period fertility rates were declining in the period where data was missing, from mid1960s to 1970s. Thus we are underestimating fertility in these periods. Consequently, we are underestimating cohort fertility for the cohorts that were in their prime childbearing ages in these years, mainly cohorts born from 1950 to 1965 . Had we had accurate information on fertility for these periods, the estimated cohort fertility rates for cohorts born in approximately 1950-1965 would have been higher. This would have made the observed levelling off and reversal in cohort 
fertility trends in the most recent cohorts even more pronounced than it is with current data and conservative estimates for some of the 1950s and 1960s cohorts.

Prior research suggests that various dimensions of socioeconomic development predict levels and trends in period fertility among developed countries. In particular, the overall level socioeconomic development, proxied by the Human Development Index (HDI) (Myrskylä et al. 2009), Gross Domestic Product (GDP) per capita (Luci and Thévenon 2010), and gender equality (Feyrer et al. 2008; McDonald 2000) have received attention as determinants of period fertility. In an application of the new cohort fertility forecasts, we study whether these factors would emerge as determinants cohort fertility. In particular, we tested whether gender equality, measured by the World Economic Forum’s Global Gender Gap Index (GGG), and economic development, measured by log of purchasing power adjusted Gross Domestic Product per capita (GDP) predict of cohort fertility by calculating the correlations fertility for the 1979 birth cohort and the value of these indexes for the year 2009 when the 1979 cohort was at its peak childbearing age.

We measures gender equality using the readily available World Economic Forum’s Global Gender Gap index (GGG) (source: http://www.weforum.org/en/index.htm). The Global Gender Gap index measures gender equality, with high values indicating high equality and low values low equality. There are three basic concepts underlying the Global Gender Gap Index. First, it focuses on measuring gaps rather than levels. Second, it captures gaps in outcome variables rather than gaps in means or input variables. Third, it ranks countries according to gender equality rather than women's empowerment. The measure is constructed from four sub indices: economic participation and opportunity; educational attainment; political empowerment; and health and survival. 
GDP per capita measures the average national income. We use GDP per capita at 2007 US dollars expressed in purchasing power parity for year 2009, obtained from the World Bank Development Indicators Database (http://data.worldbank.org/indicator).

The Human Development Index, produced by the United Nations Development Programme (UNDP), is a composite statistic used to rank countries by level of overall socioeconomic development. The statistic is composed from data on life expectancy, education and per-capita GDP collected at the national level. We use data on HDI for year 2009, obtained from the United Nations Development Programme (http://www.undp.org/).

Some of the values for GGG, GDP or HDI are not available for all countries and regions. First, they are available only for Germany as a whole, but not separately for former east and west. We use the overall German values for both former east and west Germany. Second, HDI, GDP and GGG are all missing for Taiwan in the original sources. Therefore we exclude Taiwan from the analysis of the determinants of cohort fertility.

\section{Methods}

We use a simple new method for forecasting the completed childbearing of cohorts that are still in their 30s and 40s. The method is based on limited extrapolation of age-specific trends and allows the age-specific trend observed over the last 5 years to continue for another 5 years. The forecasting model is embedded in a more general family of forecasting models; an appealing feature of these models is that they allow both a straightforward comparison to other models within the same family, and estimation of the forecast uncertainty. 
Our forecasting model, which is inspired by the Lee-Carter model for period mortality and the Lee model for period fertility, is based on the equations

(1) $F(t)=A+b K_{t}$

(2) $K_{t}=K_{t-1}+\delta+\varepsilon_{t}$

where in the equation (1) $F(t)$ is the vector of age-specific fertility rates at period t (for country c, but for simplicity the country subscript has been suppressed); A is the baseline age-schedule of fertility; b is a vector of coefficients that define how fertility at a given age changes with respect to $\mathrm{K}$; and $\mathrm{K}(\mathrm{t})$ is a scalar-valued time-series process capturing changes in both quantum and tempo of fertility. The equation (2) describes the assumed time-series process for $\mathrm{K}(\mathrm{t})$; we adopt the simple but flexible random walk with drift model.

We conduct the forecasting only for ages 30 and above. This is because the latest cohort for which we calculate the uncertainty are born in 1979, and are already 30 at the year from which the fertility forecasting starts.

The baseline age-schedule $\mathrm{A}$ is age-specific fertility rates in the last observation period. The vector $b$ describes how fertility changes with respect to $\mathrm{K}$ and is estimated as the age-specific trend in fertility over the last five observations. Within the family of models described by the equations (1) and (2), also alternative ways to estimate b would be possible: for example, one could use shorter or longer intervals to estimate the trend. We considered estimating the trend from the last 3, or the last 10 observations. This did not change the results when compared to using the last 5 observations. 
The time-series process $\mathrm{K}$ is not directly observed, but there is a straightforward way to calculate K. First, calculate the residual in observed fertility that is left after subtracting the baseline fertility: $\tilde{F}(t)=F(t)-A$. Then estimate $\mathrm{K}$ from the regression model $\tilde{F}(t)=K_{t} b$, where $\mathrm{b}$ is observed and $\mathrm{K}$ is the estimated parameter. Replicating the process for the required years - in our case, last five years -results in a time series $K_{t-4}, K_{t-3}, K_{t-2}, K_{t-1}, K_{t}$ where the last $\mathrm{K}(\mathrm{t})$ is by design zero. The drift parameter $\delta$ in equation (2) is estimated from the time series $K_{t-4}, K_{t-3}, K_{t-2}, K_{t-1}, K_{t}$.

Given the estimated parameters $b$ and $\delta$ (and starting value $K_{t}$, which is zero) we can predict period fertility into the future with $\hat{F}(t+j)=A+b \hat{K}_{t+j}$, where $K_{t+j}=j \delta$, and estimate cohort fertility rates from the forecasted age-period fertility surface. However, unlimited forecasting with a trend process (such as the random walk with drift) is potentially dangerous, and a balance could be sought between using the existing trends to inform us about the future, and being realistic about how long the trends might continue. A simple way to achieve this is to redefine the future of the process $\mathrm{K}$ to be $K_{t}=K_{t-1}+\delta+\varepsilon_{t}$ up to a certain time period, and then set the trend $\delta$ to zero. The most conservative approach is to set $\delta$ to zero immediately: none of the past trends will continue into the next year. Alternatives include letting the trend continue for some years - we considered 5 years - or ad infinitum. We studied forecasting accuracy with these three alternatives (for details see the section Forecast Accuracy) and found that the 5-year extrapolation had the best forecast accuracy. Therefore we use that in the rest of the paper.

In addition to allowing easy comparison with other models, embedding the 5-year extrapolation of age-specific fertility trends into the forecasting family described by equations (1) and (2) is particularly useful for deriving bounds for the forecast uncertainty. The source of uncertainty in 
the forecasts is the uncertainty in the process K. This uncertainty translates into uncertainty in future period fertility rates, which in turn accumulate into uncertainty in the cohort fertility rates. We capture this total uncertainty by simulating a large number of future paths of $\mathrm{K}$, calculating the resulting cohort fertility rates for each path, and summarizing the uncertainty as the interval that captures $95 \%$ of the simulated cohort fertility rates. Our simulation takes into account both the uncertainty in the drift and the random shocks to the process $\mathrm{K}$.

In practice, the simulation of the uncertainty proceeds as follows. We first simulate the drift parameter from the estimated from the normal distribution with mean $\delta$ and variance estimated from the time series $K_{t-4}, K_{t-3}, K_{t-2}, K_{t-1}, K_{t}$. We then fix the drift (for 5 years, after which the drift becomes zero) and simulate the random shocks $\varepsilon_{t}$. When combined, these result in one possible future path of $\mathrm{K}$, one possible age-period fertility surface, and one possible set of cohort fertility rates which are obtained from the diagonal of the age-period fertility surface. We repeat this process 10,000 times and calculate the interval that captures $95 \%$ of the simulated cohort fertility rates; the mean of these simulations is the basic 5-year extrapolation.

Prior research includes several alternatives for forecasting cohort fertility. Some of these involve complicated parametric models, while a few of the others combine parametric methods with extrapolation (Chandola, Coleman and Hiorns 1999; Evans 1986; Frejka and Calot 2004; Frejka and Sardon 2004; Li and Wu 2003; Peristera and Kostaki 2007; Schmertmann 2003). Although the performances of all these methods vary, it is commonly agreed that for short-term forecasts (i.e. forecasts made for the next couple of decades, such as ours), more complex parametric models have not been more accurate than simple geometric ones (Lee, Carter and Tuljapurkar 1995; Rogers 1995; Smith 1997). Therefore we test our 5 year extrapolation method against the 
simple geometric alternatives. These are the freeze rates method which assumes that the last observed age-specific fertility rates will persist into the future (the age-specific rates are frozen to the level of last observation and copied forward), and linear extrapolation with a fixed trend which assumes that any observed age-specific trend, observed over the last five years, will continue as such into the future. ${ }^{1}$ Our preferred new forecasting method, linear extrapolation 5 years into the future, strikes a balance between the immediate freezing of rates and extrapolation with fixed trend. This method lets the age-specific trends continue for five years, and then freezes them. We use the last five observations to calculate the trend in each age group.

We tested the three methods with completed cohort data for the 1950-1965 cohorts for each twenty three countries for which the data was available. We let the methods use the data only up to certain truncation age (ages 30, 31, .., 45), forecast completed cohort fertility with this limited data, and compare the results to the known completed fertility. The results of the comparison, discussed in detail in the section Forecast Accuracy, showed that the new 5-year extrapolation markedly improves the forecast accuracy over the competing methods. In particular, when evaluated using historical data, the new method has a markedly lower bias, variance, and root mean squared error than the alternative methods. 


\section{RESULTS}

\section{Cohort fertility forecasts}

Figure 1 shows the key result of our analysis. The figure plots for 37 developed countries the average period fertility over the years 1980-2009 and the average cohort fertility for the 19501979 birth cohorts. These cohorts were in their prime childbearing ages in the years 1980-2009. The figure shows that the decline in period fertility has been largely an artefact of later - not less - childbearing: while the average period fertility across the 37 developed countries declined from approximately 2 in 1980 to below 1.5 in early 2000s, the average cohort fertility has remained on a much higher throughout the 1950-1979 cohorts and averages 1.8 children per woman for the 1975 birth cohort. Across the 37 countries, the late 1970s cohorts have as much or more children on average the cohorts born in the mid-1970s.

\section{FIGURE 2 ABOUT HERE}

Figure 2 shows the new cohort fertility forecasts by country and region for the 1950-1979 birth cohorts for developed countries that have experienced prolonged below-replacement period fertility. The regions are arranged by their most recent cohort fertility level. While there is variation across regions, on the whole the regional averages suggest that the long-term trend in lifetime fertility decline is flattening or has reversed not just when averaging across the 37 countries but also in all world regions previously characterised by low fertility. Cohort fertility has been steadily increasing in the English-speaking world (Panel A), remarkably stable in the Nordic and Baltic countries (Panel B), and reversed direction from decline to rise in Continental Europe (Panel C). In Eastern Europe (Panel D) and the Mediterranean (Panel E), decades of 
decline have come to an end. Only in East Asia (Panel F) cohort fertility continues to fall, but even here the decline is levelling off.

Each region shows variation. Notable in the English speaking world are the increases in the U.S. and in the United Kingdom, both with cohort fertility exceeding 2. Within Scandinavia, Sweden is remarkable for decades of nearly constant cohort fertility despite swings in period fertility. Denmark is notable for an early rise in cohort fertility, attributed in part by some to generous subsidies of artificial reproductive technology (Andersson et al. 2009). Only in Lithuania cohort fertility is considerably below replacement; however even there lifetime fertility is increasing and with 1.7 for the 1975 cohort well above the period rates which were below 1.3 for much of the 1990s and 2000.

In Continental Europe, fertility fell for the generations born in the 1960s but is rising for the 1970s cohorts. The region's highest and lowest fertility populations - France (fertility for the 1975 cohort 2.0) and Germany (1.6) - have parallel paths occurring for the same generations, albeit at different levels. Lifetime fertility for Continental Europe averages 0.1-0.3 children per woman above the period rates that prevailed in the 1990s, reaching 1.8 for the most recent generations.

Eastern Europe shows a distinct pattern. For the 1950s cohorts, completed fertility was on average 2. Cohorts born in 1960s were in their prime childbearing years when the Soviet Union collapsed. In response to the wholesale societal transformation, men and women reduced having children at the young ages that characterised Eastern European family formation. Fertility was universally postponed and to some extent foregone, but cohorts coming of age after the mid1990s show no sign of continued decrease. Instead, cohort fertility has stabilised to 1.6 children 
per woman, a level much higher than the period rates which fell below 1.3 in each country of the region in the post-Soviet world.

Among the Mediterranean countries, only Portugal continues to experience declining cohort fertility, whereas Greece and even the poster countries of low fertility, Italy and Spain, see levelling or even slight increase.

The lowest observed cohort fertility rates are in East Asia. Here completed family size declined close to 1.4 for the mid- to late 1970s cohorts. Cohort fertility is continuing to fall in Taiwan, Singapore, and South Korea, but has increased slightly for recent cohorts in Japan.

\section{TABLE 2 ABOUT HERE}

The results shown in Figure 1 and Figure 2 challenge the worries about continued decline of birth rates in the developed world. Table 2 summarizes the cohort fertility trends, and show that in our sample of 37 countries that covers all world regions with prolonged below-replacement period fertility, average lifetime fertility for the 1975 cohorts is 1.77 . The mean change over the 1975-79 cohorts is flat. The mean, however, is heavily influenced by a handful of countries with very rapid fertility decline such as Korea and Taiwan. An alternative measure of the average change that is robust to outliers is the median, which increased by .02 children per woman over the birth cohorts 1975-1979.

The statistics on change in Table 2 show that over the cohorts 1950-60 and 1960-70 most countries recorded declining fertility. For example, only three countries — the US, Luxembourg, and Denmark—-had higher fertility for the 1970 cohort than for the 1960 cohort. For the 1970s cohorts the trajectories started to change, and we forecasted that in 19 of the 37 countries fertility 
for the 1975 birth cohort will be at least as high as for the 1970 cohort. As we show in the section on forecast accuracy, uncertainty for these cohorts is very small. Our forecasts suggest that the positive trend in cohort fertility intensified in the latter half of the 1970s, so that in a majority of the countries, 25 out of 37, fertility for the 1979 birth cohort will be at least as high as for the 1975 cohort. These results suggest that the long-term fertility decline in the developed world has come to an end or at least stalled.

The proportion of eventual completed fertility observed for the most recent birth cohort (1979) is on average 56 percent, and 44 percent of the fertility is forecasted. This is a larger fraction than is often forecasted; for example, Frejka and Sardon (2004) restricted their forecasts to situations in which only 15 percent of completed fertility remained unknown. The larger fraction of forecasted fertility influences the forecast uncertainty. We show below that while uncertainty up to the 1975 birth cohort is very small, for the 1979 cohort the standard errors of the forecasts increase but remain on average only 2 percent of the completed cohort fertility.

Comparing the new country-specific cohort fertility forecasts to the period fertility rates that dominate policy discussion results in remarkable differences. By 2009, 19 of the 37 countries had experienced period fertility below 1.3, a threshold often termed "lowest-low" fertility, and 25 had period fertility below 1.5. In the cohort perspective, and including cohorts born up to 1979, only seven countries are characterized by fertility below 1.5, and no country is forecasted to go below 1.3. These differences suggest that much of he observed very low fertility has been attributable to later, not less, childbearing. Sobotka (2004) and Goldstein, Sobotka, and Jasilioniene (2009) reached similar conclusions. 


\section{Cohort fertility in China}

Two regions are excluded from our main analysis: South America, because it cannot be characterized as a low-fertility region as below-replacement fertility is only emerging in a few of the region's countries (World Bank 2008), and China because of lack of data.

While fertility estimates for China are highly uncertain (Morgan, Zhigang and Hayford 2009), we provide here a tentative analysis of the cohort fertility trends from the 1950s to the late 1970s birth cohorts. Regarding period fertility, several international agencies report numbers that suggest that the decline in fertility has stalled. The World Bank development indicators database reports that the period total fertility rate for China fell from 2.3 in 1990 to 1.8 in 2000, and has since been stable between 1.7 and 1.8 (World Bank 2008). The United Nations also estimates the 1995-2010 average total period fertility rate to be 1.8 (United Nations 2008 World Population Prospects, http://esa.un.org/unpp/). Other sources, which are mainly based on survey data, suggest that Chinese period fertility reached 1.5 already in the early 1990s and has then remained stable between 1.4 and 1.5 (Guo 2009; Morgan et al. 2009). Morgan et al. (Morgan, Guo and Hayford 2009), in turn, estimate that for the 1970s cohorts fertility has been stable at 1.7 children per woman.

Due to the high uncertainty and conflicting estimates, but undeniably large importance in global population trends, China is often considered separately from other countries in demographic analyses (Lutz and Samir 2010). Here we present suggestive evidence that cohort fertility rate in China for the 1970 s cohort is approximately 1.7 children per woman, a figure comparable to the average in Continental Europe. The calculations are done with data from national sample-based birth statistics and a fertility data collection in China (National Bureau of Statistics of China 
1987-2010; Yao 1995), and the forecast is based on the same linear extrapolation five years into the future that we use for the other 37 countries. For China we have data only up to 2008, so the trend in age-specific fertility rates is estimated from the last five years (years 2004-2008).

Our resulting cohort fertility estimates are subject to large uncertainty, as fertility rates had to be interpolated over the missing years 1982-1985, 1987-1988, 1991-1993, and 2000-2001; because the 1994-1999 data came in five year age groups and had to be disaggregated to one-year age groups; and because all the data comes from surveys which are subject to small sample variation and potential bias.

\section{FIGURE 3 ABOUT HERE}

Figure 3 shows the estimated cohort fertility trajectories for China. These results, while undeniably subject to large uncertainty, suggest that cohort fertility declined sharply until the 1970s cohorts, but then stabilized to a level approximately 1.7 children per woman. These results are consistent with Morgan et al. (Morgan et al. 2009), who write: “[In China] a reasonable estimated range for mean completed fertility for women born in the 1970s and later is 1.6 to 1.7 , higher by 0.1 or 0.2 children compared to the period estimates for the 1990s.”

We conclude that the available data and published research for Chinese cohort fertility patterns suggests that decline in cohort fertility in China leveled off for the 1970s cohorts. Cohort fertility for the cohorts born in the 1980s or later will be determined by future fertility rates. 


\section{FORECAST ACCURACY}

How certain are our forecasts? We assessed the uncertainty in three ways. First, we used the simulation described in the section Methods to derive the 95\% confidence bounds for the country-specific cohort fertility forecasts. Figure 4 illustrates the uncertainty for 6 selected countries and Table 3 summarizes the average uncertainty across the 37 countries. Appendix Figure A. 1 shows the confidence bounds for each of the 37 countries.

\section{FIGURE 4 ABOUT HERE}

\section{TABLE 3 ABOUT HERE}

Of the selected 6 countries shown in Figure 4, two countries - UK and France - exhibit a fertility trajectory that is with high likelihood positive as even the lower bound of the 95\% confidence interval trends upwards for the late 1970s cohorts. Two countries, Japan and Bulgaria, illustrate a pattern in which at a minimum stabilization of decline is likely, as the lower bound of the $95 \%$ confidence interval has stopped declining for the 1970s cohorts. For these two countries, however, the case for increasing cohort fertility is less strong as it is for UK and France. Slovakia and Korea, in turn, illustrate a fertility trajectory that is with high likelihood negative for the late 1970s cohorts: even the upper bound of the 95\% confidence interval trends downwards for these countries.

Table 3 summarizes the forecast uncertainty expressed in terms of the width of the 95\% confidence interval. The average width of the confidence interval is very narrow until and including the 1975 birth cohort, only 0.06 children (+/- 0.03 children) per woman. For the later cohorts, the length of the confidence interval starts to increase rapidly, being 0.14 children (+/- 
0.07 children) per woman for the 1979 birth cohort which is the latest cohort for which we construct the forecasts. When compared to the total forecasted fertility, however, this is only $8 \%$, or $+/-4 \%$.Interestingly, the ratio of the width of the confidence interval to the amount of forecasted part of fertility is virtually constant across the cohorts, implying that it does not depend on the age at which forecasting starts.

It is not straightforward to derive the aggregated uncertainty for the 37 countries from the country-specific uncertainties, as this would require information about correlations in fertility across countries. An upper bound, however, is easily obtained by assuming an extreme positive correlation in the underlying process K across countries. With this assumption, the width of the confidence interval for the average cohort fertility rate for the 1979 birth cohort across the 37 countries is $[1.70,1.84]$.

Second, we considered a scenario-type bounding of our estimates by assuming two extreme scenarios: one using the freeze rates method which assumes that current age-specific rates prevail in the future, and one in which the past trends in age-specific rates continue uninterrupted into the future. The freeze rates method is known for its tendency to underestimate fertility, providing a lower bound. The long-term extrapolation assumes that recent fertility increases will continue for a long time, providing an upper bound.

Our finding of a reversal in the trend toward low fertility is robust across these extreme scenarios. The 5-year extrapolation results in an average fertility for the 1975 cohort of 1.77 . The freezerates forecast is marginally lower at 1.73 , and the long-term extrapolation is 1.79 . The freezerates, the 5-year extrapolation, and the long-term extrapolation predict, respectively, that in 19, 27, or 28 countries fertility is flat or increasing over the 1975-79 cohorts, or averages above 1.7 
(e.g., under freeze-rates, countries such as Australia, the US, Sweden, and Denmark are forecasted to have decreasing cohort fertility, though at a relatively high level). For countries with cohort TFR below 1.7 over the 1975-79 cohorts, the 5-year and long-term extrapolations predict that only eight have declining fertility. The freeze-rates method indicates that 18 countries have fertility below 1.7 and declining. Even for this pessimistic scenario, however, in the majority of countries (19/37) cohort fertility has stopped declining or exceeds 1.7.

Third, we applied our new forecasting method to historical data (1950-65 cohorts) and estimated the bias and root mean squared error (RMSE) by truncation age (for details see the Appendix, in particular Figure A.3). When judged against historical data, our new forecasting method proves accurate: The average bias was small but downward, suggesting that our forecasts may be conservative. For example, for truncation age 30 (corresponding to the 1979 cohort when data is available up to 2009) the bias was -0.03 ( $1 / 33^{\text {rd }}$ of a child per woman). The bias decreased rapidly with age, being at ages 33 and above less than $1 / 75^{\text {th }}$ of a child. The total forecast error measured by the RMSE among the 1950-1965 cohorts is less than 0.02 units (less than 1 percentage point in relation to completed fertility) when forecasting starts from age 33. When forecasting starts from age 30, the average forecasting error is still less than 2 percentage points. ${ }^{2}$ 


\section{IMPACT OF THE LATE 2000S RECESSION}

We studied the impact of the late 2000s recession on our new cohort fertility forecasts by conducting a sensitivity analysis in which we compare forecasts obtained with data that is not affected by the recession to forecasts obtained with data that is influenced by the recession.

We first used the 5-year extrapolation with fertility data only up to 2008 - which is very little if at all affected by the late 2000s recession - to produce a set of new cohort fertility estimates. We then compared these estimates to our main estimates which use data up to the year 2009, and are influenced by the recession. However, the impact of the recession on fertility may be markedly stronger than the difference observed between forecasts that cut the data in 2008 and forecasts that use data up to 2009: the recession started in many countries in 2008, and is likely to have an influence on fertility for a longer period than just the following year. To some extent, our forecasting method takes this into account: the method is based on trends, and the observation for the year 2009 influence the estimated trend, hence having an impact several years into the future. Nevertheless, to err on the conservative side, we conducted a simulation in which we assume that the drop in forecasted cohort fertility rates obtained using data up to 2009 versus using data only

up to 2008 is only (i) half, (ii) $1 / 3^{\text {rd }}$, or (iii) $1 / 4$ th of the total impact of the recession. That is, we magnify the fertility drop by a factor of two, three or four, and study the implications of these extreme scenarios which assume a prolonged impact of the recession on fertility.

\section{TABLE 4 ABOUT HERE}

Table 4 shows the average cohort fertility rates in our sample of 37 countries, the forecasted number of countries with cohort fertility of at least 1.75 fertility for the 1979 birth cohort, and the number of countries experiencing the specified fertility change over the 1975-79 and 1970-79 
birth cohorts across the simulated recession scenarios. The baseline forecast is the same as we reported in Table 2. The alternative scenarios show what the forecasted fertility rates would be if the impact of the recession is assumed to be 2,3 , or 4 times larger than the difference in forecasted cohort fertility rates using data up to 2009 or 2008. The results in Table 4 show that the forecasts are relatively robust to these scenarios. The average cohort TFR decreases when we increase the magnitude of the simulated recession effect. However, even in the scenario that multiplies the difference in forecasted cohort fertility obtained with data up to 2009 versus 2008 by a factor of four, the average cohort TFR remains above 1.7 at 1.73 . In the same scenario, we observe that 19 of the 37 countries have either flat or increasing cohort fertility over the 1975-79 birth cohorts, while 18 have decreasing fertility. For the change over the 1970-79 birth cohorts, this extreme scenario predicts that 14 countries have flat or increasing fertility. The difference with respect to the 1975-79 change is explained by the fact that the 1970 cohort was virtually immune to the recession effect, whereas the 1975 cohort's fertility is forecasted to drop on average from 1.77 to 1.74 under this scenario (data not shown). In the other scenarios in which the simulated recession effect is multiplied by a factor of 2 or 3 , the slope of cohort fertility trajectories is even more positive. In particular, across all scenarios more than half of the countries have either flat or increasing fertility over the 1975-79 birth cohorts.

As an additional robustness check, we conduct a similar analysis using the change in forecasted fertility with data up to 2010 versus 2008 as a proxy for the effect of the recession on fertility. This change can be calculated for 23 countries for which 2010 data are available; for the other countries we use the 2009 vs. 2008 change. The lower panel of Table 4 shows the results. Across all scenarios, the average cohort TFR stays above 1.70. Moreover, in all scenarios the majority of countries have either flat or increasing fertility over the 1975-79 birth cohorts. For example, in 
the most extreme scenario in which the fertility decline observed using data up to 2010 versus 2008 is multiplied by 4, average fertility for the 1979 birth cohort is 1.72, and 20 countries have either flat or increasing fertility for the late 1970s cohorts.

Overall, our analysis shows that a continuing or worsening recession is unlikely to produce large changes in completed fertility for cohorts born through the late 1970s, although it could influence later cohorts and alter the prospects of a long-term trend-reversal. 


\section{APPLICATIONS OF THE NEW COHORT FERTILITY FORECASTS}

We illustrate the usefulness and importance of the new cohort fertility forecasts with two applications. First, we analyze the long-term demographic implications of a fertility rate that is

close to the newly estimated cohort fertility rate, against the counterfactual that fertility would stay at the levels recently observed in the period perspective. Second, we analyze the macro level determinants of the national level differences in cohort fertility rates.

\section{Long-term effects of fertility changes on demographic outcomes}

Even small differences in birth rates can have large long-term implications for population change, potential levels of migration needed to maintain population size, and population aging, all of which depend on how much fertility differs from the replacement level fertility of about 2 children per woman. We illustrate this by a projection of the European population from year 2000 into the future. For this projection we considered two levels of fertility, 1.50 and 1.75 children per woman, the former approximating the current average period total fertility rate and the latter the average lifetime fertility for the 1970s cohorts across the developed world (see Figure 1). In both scenarios we used a no-migration and replacement-migration variant. Life expectancy was assumed to continue to increase according to the United Nations long-term projections (UN 2011). Replacement fertility scenarios were constructed by calculating the rate of immigration at age 20 that would be required to keep the population size constant. For simplicity, the migrants were assumed to have the same fertility as the native population.

TABLE 5 ABOUT HERE 
The results of the projections, shown in Table 5, confirm that small changes in fertility have large long-term implications. Under no migration, the population size in the TFR 1.5 scenario falls from 483 million in 2000 to half by 2100, and to only 94 million by 2200 . With the TFR of 1.75 and no-migration, the population doesn't fall to half until nearly a century later, reaching 221 million in 2200, more than twice as large as the lower-fertility case.

The difference is also seen in terms of age structure. Mean ages are about 4 years older when the TFR is 1.5 , compared to 1.75 . The old age support ratio is also about $20 \%$ higher when fertility is 1.75 instead of 1.50 .

The stream of migrants required to maintain population size also differs dramatically if fertility is 1.75 rather than 1.50 . The migration streams in the long term are 0.66 million with the higher fertility and 1.32 million with the lower fertility. Since education of the children of immigrants is often seen as a concern, one can also quantify the ratio of children of foreign-born parents to children of native-born. In the replacement migration case with fertility of 1.75 , this ratio is about 1 to 7 , but when fertility is 1.50 , this ratio is 1 to 3 .

\section{Determinants of differing cohort fertility levels}

While cohort fertility has stopped declining in most developed countries, there is still a wide spectrum of lifetime fertility levels across the industrialized world. For the cohort 1975, fertility ranges from above replacement (Iceland 2.31, USA 2.22, New Zealand 2.18, Ireland 2.14) to below 1.5 (Italy 1.46, Singapore 1.43, Japan 1.43, Spain 1.41).

What is driving these differences in levels and trends of lifetime fertility? For increases in period fertility, a number of candidate explanations have been suggested, ranging from gender equality 
(Feyrer et al. 2008; McDonald 2000) and family and labour policies (Adsera 2004; Gauthier 2007) to economic and human development (Luci and Thevenon 2010; Myrskylä et al. 2009). In contrast, much less is known about the reversal of lifetime fertility. In an application of the new cohort fertility forecasts, we studied whether these factors would emerge as determinants cohort fertility. In particular, we tested whether gender equality, measured by the World Economic Forum’s Global Gender Gap Index (GGG), overall socioeconomic development, measured by the United Nations Development Programme’s Human Development Index (HDI), and economic development, measured by log of purchasing power adjusted Gross Domestic Product per capita (GDP) predict of cohort fertility by calculating the correlations fertility for the 1979 birth cohort and the value of these indexes for the year 2009 when the 1979 cohort was at its peak childbearing age. ${ }^{3}$

\section{TABLE 6 ABOUT HERE}

The results, shown in Table 6, suggest each of these three factors - GGG, HDI, and GDP - is positively correlated with cohort fertility. However, as shown in Table 3, gender equality, measured by GGG, is markedly stronger determinant of cohort fertility than HDI or GDP: GGG explains 51\% of the cross-country variation in fertility for the 1975 birth cohort, whereas HDI explains $18 \%$ and GDP only $10 \%$. Moreover, in a model which includes gender equality and both HDI and GDP, both HDI and GDP lose their predictive power but gender equality continues to be positively correlated with cohort fertility. This cross-sectional regression of the 1979 cohort fertility on gender equality in year 2009 implies that a 10-point difference in the equality index is associated with a .34 unit difference in fertility $(\mathrm{p}<.001)$, net of HDI and GDP. ${ }^{4}$ These results show that GDP and HDI do not predict fertility net of gender equality, but gender equality continues to be a strong predictor of cohort fertility even after controlling for GDP and HDI. This 
suggests that gender equality may have a critical mediating role in linking socioeconomic development to increasing fertility.

\section{FIGURE 5 ABOUT HERE}

Figure 5 illustrates the cross-country association between gender equality and cohort fertility. The association is approximately linear. In countries with gender equality index in the highest third (>.75), 1979 cohort fertility averages 1.92 . For countries with gender equality in the middle third (.70-.74), 1979 cohort fertility averages 1.81 . For countries in the lowest third, 1975 cohort fertility is 1.60. Additional regressions (not shown) show the positive correlation between gender equality and fertility is not driven by any single country cluster, but positive correlation persist after deleting any of the clusters.

While much fertility variation is not explained by gender equality - for example, within a gender equality window .74-.76, cohort fertility varies from 1.41 (Spain) to 2.22 (US) - on the whole, gender equality is a strong predictor of completed family size, explaining $51 \%$ of fertility variation for the 1979 cohorts across industrialized countries.

As a robustness check, we studied whether the observed positive correlation was between gender equality and cohort fertility was depends on the specific indicator of gender equality. We considered the UNDP’s Gender-related Development Index and the UNDP’s Gender Empowerment Measure. Gender-related Development Index GDI measures achievement in the same basic capabilities as the HDI does, but takes note of inequality in achievement between women and men. The methodology imposes a penalty for inequality, such that the GDI falls when the achievement levels of both women and men in a country go down or when the disparity between their achievements increases. Thus the GDI is simply the HDI discounted, or adjusted 
downwards, for gender inequality. While the GDI focuses on expansion of capabilities, the GEM is concerned with the use of those capabilities to take advantage of the opportunities of life. The measure takes into account the following components: seats in parliament held by women (\% of total); female professional and technical workers (\% of total); ratio of estimated female to male earned income; year women received right to vote; year a women became presiding officer of parliament or of one of its houses for the first time; and women in ministerial positions (\% of total). Both GDI and GEM turned out to be positively and statistically significantly $(\mathrm{p}<.05)$ correlated with completed fertility for the 1979 cohort (results not shown). In our reported regressions we show the results for GGG because (i) this is the only gender equality measure that is to any extent independent of economic development; that is, also poor countries can at least in principle rank high in equality; and (ii) the correlations between GGG and cohort fertility are stronger than for the other gender equality measures.

The documented cross-national correlation between cohort fertility and gender equality does not demonstrate a causal relationship, and additional analyses investigating the potential causal role of gender equality in determining cross-national variation, and potentially also within-country variation, in cohort fertility is needed before strong conclusions can be made. However, the positive correlation is indicative of the context that facilitates increasing cohort fertility, and illustrates the usefulness of the new cohort fertility forecasts in being potentially helpful in shedding light on the determinants of fertility. 


\section{DISCUSSION}

Our forecasts of cohort fertility use a large set of countries and a new method for estimating the completed fertility of women who are still in their 30s or 40s. Our results counter concerns about the continued decline of birth rates in the developed world (Lutz, Skirbekk, and Testa 2006). In our sample of 37 countries from all world regions with prolonged below-replacement period fertility, forecasted cohort fertility is often not much different from 2 children per woman, even in many countries where period fertility rates fell below 1.3. Forecasted average lifetime fertility for the 1979 cohorts is 1.77 , and 25 countries recorded either increasing or stable fertility for the late 1970s cohorts, while 12 had a negative fertility trajectory. Our results suggest that the long-term fertility decline in the developed world is flattening or reversing in many countries previously characterized by low fertility.

The observed differences between lifetime fertility and the period fertility rates that dominate policy discussion are remarkable. By 2009, 19 of the 37 countries had experienced period fertility below 1.3, a threshold that has been termed lowest-low fertility. In the cohort perspective, and including cohorts born up to 1979, only seven countries experienced fertility below 1.5, and no country is expected to fall below the threshold of lowest-low fertility. These differences confirm that much of the very low fertility is the result of later, not less, childbearing.

The documented gap between cohort and period fertility rates is consistent with the literature on tempo-adjusted period fertility rates. The tempo adjustments aim to estimate what the period total fertility rate would have been in the absence of changes in the timing, or tempo, of fertility. Prior research (Bongaarts and Sobotka 2012; Goldstein, Sobotka, and Jasilioniene 2009; Sobotka 2004) has already argued that a substantial part of the fertility decline in the developed world to 
low- and lowest-low levels is attributable to fertility postponement, and that the recent increases in period TFR have been driven at least in part by a decrease in the fertility-suppressing tempo effect. The tempo adjustments, however, do not describe the fertility of real cohorts but refer to synthetic cohorts. Our analysis provides a direct approach to the question "how many children are women of real birth cohorts having" by estimating the cohort fertility rate. We find that women in many countries will have more children than the non-adjusted period TFR suggests.

Our forecasts are based on a method in which past age-specific fertility trends are allowed to continue 5 years into the future. Evaluated against historical data, this approach appears quite accurate; in particular it performed much better than the freeze-rates approach. It also outperformed alternative extrapolation lengths. Our evaluation of forecast uncertainty suggested that it is relatively small, with an average expected forecast error of less than $+/-.03$ children per woman for the 1975 cohort, and less than +/-.06 children (approximately 3 percent of completed fertility) for the 1979 cohort. Thus, while the forecast interval widens rapidly when moving to later cohorts, our results up to and including the 1979 cohort are not critically sensitive to the forecast uncertainty.

An application of the new cohort fertility forecasts illustrate that the recent rises in cohort fertility, though numerically small, imply remarkable differences for population size, replacement migration, and aging, which all depend on how much fertility differs from replacement level fertility of about 2 children per woman. Taking Europe (EU-27) as an example, we projected the consequences of a difference of a quarter-child per woman in long-term fertility rates. In 200 years, the population would shrink from 483 million to 94 million with a fertility rate of 1.5, but to 221 million with a fertility rate of 1.75 . The migration levels needed to maintain population size would also differ, with a ratio of 1 migrant for every 3 births required if fertility were 1.5 but 
1 migrant for every 7 births if fertility were 1.75 . Population aging would also be less dramatic. Even with continued increases in longevity, the population would in 200 years be on average 4 years older, a mean age of 56, with a fertility rate of 1.5 as compared to 1.75 .

Another application illustrating the usefulness of the new cohort fertility forecasts analyzed the determinants of cohort fertility. While cohort fertility has stopped declining in most developed countries, there is still a wide spectrum of lifetime fertility levels across the industrialized world. For the cohort 1975, fertility ranges from above replacement (Iceland 2.31, USA 2.22, New Zealand 2.18, Ireland 2.14) to below 1.5 (Italy 1.46, Singapore 1.43, Japan 1.43, Spain 1.41). We analyzed whether general socioeconomic development, per capita income, or gender equality all factors which have been suggested to be important for period fertility - would explain any of the observed variation in cohort fertility rates. Per capita income and general socioeconomic development, measured by the Human Development Index, were both positively correlated with cohort fertility, but gender equality, measured by the World Economic Forum's Global Gender Gap index, emerged as a much stronger determinant of cohort fertility. Alone, it explained more than $50 \%$ of the variation in cohort fertility for the 1979 birth cohort.

While our goal in this study is to firmly document this trend, several possibilities regarding the link between cohort fertility and gender equality suggest themselves. First, it could be that the first generation of men and women to adapt to the dual-earner family had a particularly difficult task, and that as new generations come of age, they can simply cope better. Second, it could be that societies and institutions have actually responded to the difficulties of work-life balance. In an exploratory analysis we found that countries in which women's roles in politics, business, and public life are important are also those with leveling and increasing fertility: the higher the gender equality the higher the fertility. Finally, the positive association could be purely spurious, driven 
by clustering of countries by other factors. Further research focusing on the determinants of cohort fertility differences and trends could shed light on these questions; such research might benefit from the new cohort fertility forecasts provided by this paper.

Most recent debates about the long-term decline in fertility or the potential reversal of such a trend have drawn information from the period TFR. While the period measure is substantially distorted during times of fertility postponement, the longer time horizon required for calculating cohort TFR often makes the latter an impractical alternative. Our cohort fertility forecasting method offers a new tool for examining continuity and change in fertility patterns, without having to take the tempo effect into account. It will also facilitate future research into the socioeconomic determinants of actual lifetime fertility, rather than period fertility, in the developed world. 


\section{REFERENCES}

Adsera, A. 2004. "Changing fertility rates in developing countries: the impact of labor market institutions." J Popul Econ 17:17-43.

Andersson, G., M. Rønsen, L.B. Knudsen, T. Lappegård, G. Neyer, K. Skrede, K. Teschner, and A. Vikat. 2009. "Cohort fertility patterns in the Nordic countries." Demogr Res 20(14):313-352.

Bongaarts, J. 2001. Fertility and reproductive preferences in post-transitional societies in R. A. Bulatao and J. B. Casterline (eds.), Global Fertility Transition, supplement to Population and Development Review 27. New York: Population Council, pp. 260-281.

Bongaarts, J.and G. Feeney. 1998. "On the quantum and tempo of fertility." Popul Dev Rev 24(2):271-291.

Bongaarts, J.and T. Sobotka. 2011. "Demographic explanations for the recent rise in Europe's fertility: analysis based on the tempo and parity adjusted total fertility rate." in 2011 meeting of the Population Association of America.

Chandola, T., D.A. Coleman, and R.W. Hiorns. 1999. "Recent European fertility patterns: fitting curves to ‘distorted’ distributions." Popul Stud (Camb) 53:317-329.

European Commission 2005. "Green Paper “Confronting demographic change: a new solidarity between the generations.”". Commission of the European Communities. Brussels.

—. 2006. "White paper "The demographic future of Europe - from challenge to opportunity.”". Commission of the European Communities, Brussels. 
Ehrlich, P.R. 1971. The Population Bomb. Cuthogue, N.Y: Bucaneer.

Evans, M.D.R. 1986. "American fertility patterns: a comparison of white and nonwhite cohorts born 1903-56." Popul Dev Rev 12:267-293.

Feyrer, J., B. Sacerdote, and A. Stern. 2008. "Will The Stork Return To Europe? - Understanding Fertility Within Developed Nations." Journal of Economic Perspectives 22(3):3-22.

Frejka, T.and G. Calot. 2001. "Cohort reproductive patterns in low-fertility countries." Popul and Dev Review 27(1).

Frejka, T., G.W. Jones, and J.P. Sardon. 2010. "East Asian childbearing patterns and policy developments." Popul Dev Rev 36(3):579-606.

Frejka, T.and J.-P. Sardon. 2004. Childbearing Trends and Prospects in Low-Fertility Countries: A Cohort Analysis. Dordrecht: Kluwer Academic Publishers.

Frejka, T.and T. Sobotka. 2008. "Overview chapter 1: fertility in Europe: diverse, delayed and below replacement." Demogr Res 19(3):15-46.

Gauthier, A.H. 2007. "The impact of family policies on fertility in the industrialized countries: a review of the literature." Popul. Res. Policy Rev. 26:323-346.

Goldstein, J., W. Lutz, and M. Rita Testa. 2003. "The emergence of sub-replacement family size ideals in Europe." Population Research and Policy Review 22:479-496.

Guo, Z. 2009. "Why the fertility-rates in recent years notably 'pick up': Evaluation of the 2006 national population and family planning survey, zhongguo renkou kexue " Chinese Journal of Population Science 33(2). 
Kohler, H.P.and D. Philipov. 2001. "Variance effects in the Bongaarts-Feeney formula." Demography 38(1):1-16.

Lee, R.D., L. Carter, and S. Tuljapurkar. 1995. "Disaggregation in population forecasting: do we need it? And how to do it simply." Math Popul Stud 5:217-234.

Li, N.and Z. Wu. 2003. "Forecasting cohort incomplete fertility: a method and an application." Pop Stud (Camb) 57:303-320.

Longman, P. 2004. The Empty Cradle. How Falling Birthrates Threaten World Prosperity and What To Do About It. New York: Basic Books.

Luci, A.and O. Thevenon. 2010. "Does economic development drive fertility rebound in OECD countries?" in Population Association of America Annual Meeting. Dallas, TX.

Lutz, W.and K.C. Samir. 2010. "Dimensions of global population projections: what do we know about future population trends and structures?" Phil. Trans. R. Soc., B 365(2779).

Lutz, W., V. Skirbekk, and M.R. Testa. 2006. "The low fertility trap hypothesis: Forces that may lead to further postponement and fewer births in Europe." Vienna Yearbook of Population Research 2006, Austrian Academy of Sciences, Vienna.

McDonald, P. 2000. "Gender equity in theories of fertility transition." Popul. Dev. Rev. 26 427440.

Morgan, S.P., Z. Guo, and S.R. Hayford. 2009. "China’s below-replacement fertility: Recent trends and future prospects." Population and Development Review 35(3):605-629. 
Myrskylä, M., H.-P. Kohler, and F.C. Billari. 2009. "Advances in development reverse fertility declines." Nature 460:741-743.

National Bureau of Statistics of China. 1987-2010. China Statistical Yearbook 1987-2010. Beijing, C.C.S.P..

OECD. 2007. Babies and bosses: reconciling Work and Family Life. OECD, Paris.

Peristera, P.and A. Kostaki. 2007. "Modeling fertility in modern populations." Demogr Res 16(6):141-194.

Rogers, A. 1995. "Population forecasting: do simple models outperform complex models?" Math Popul Stud 5:187-202.

Ryder, N.B. 1956. "Problems of trend determination during a transition in fertility." Milbank Memorial Fund Quarterly 34:5-21.

Schmertmann, C.P. 2003. "A system of model fertility schedules with graphically intuitive parameters." Demogr Res 9:81-110.

Smith, S.K. 1997. "Further thoughts on simplicity and complexity in population projection models." Int J Forecasting 13:557-565.

Sobotka, T.and W. Lutz. 2009. "Misleading policy messages from the period TFR: should we stop using it?" Pp. 1-43 in European Demographic Research Papers. Vienna: Vienna Institute of Demography of the Austrian Academy of Sciences.

Stout, R. 2008. "Demographic Winter: Decline of the Human Family." United States. 
United Nations 2011. World population prospects: the 2010 revision. New York: United Nations, Department of Economic and Social Affairs, Population Division

Vienna Institute of Demography 2010. "European demographic data sheet 2010." IIASA and the Vienna Institute of Demography of the Austrian Academy of Sciences.

World Bank. 2008. "World Development Indicators Online Database ": World Bank.

Yao, X. 1995. Fertility Data Collection in China (Zhongguo Shengyu Shujuji). Beijing, China: China Population Publishing House. 
Figure 1. Average period total fertility rate for the years 1980-2009 and average cohort fertility rate for the cohorts 1950-1979 among 37 developed countries. For cohorts with uncompleted cohort fertility we complete the fertility using an extrapolation method in which the age-specific trend in fertility observed over the last 5 years are allowed to continue for another 5 years. See the section Methods for details of the method and data.

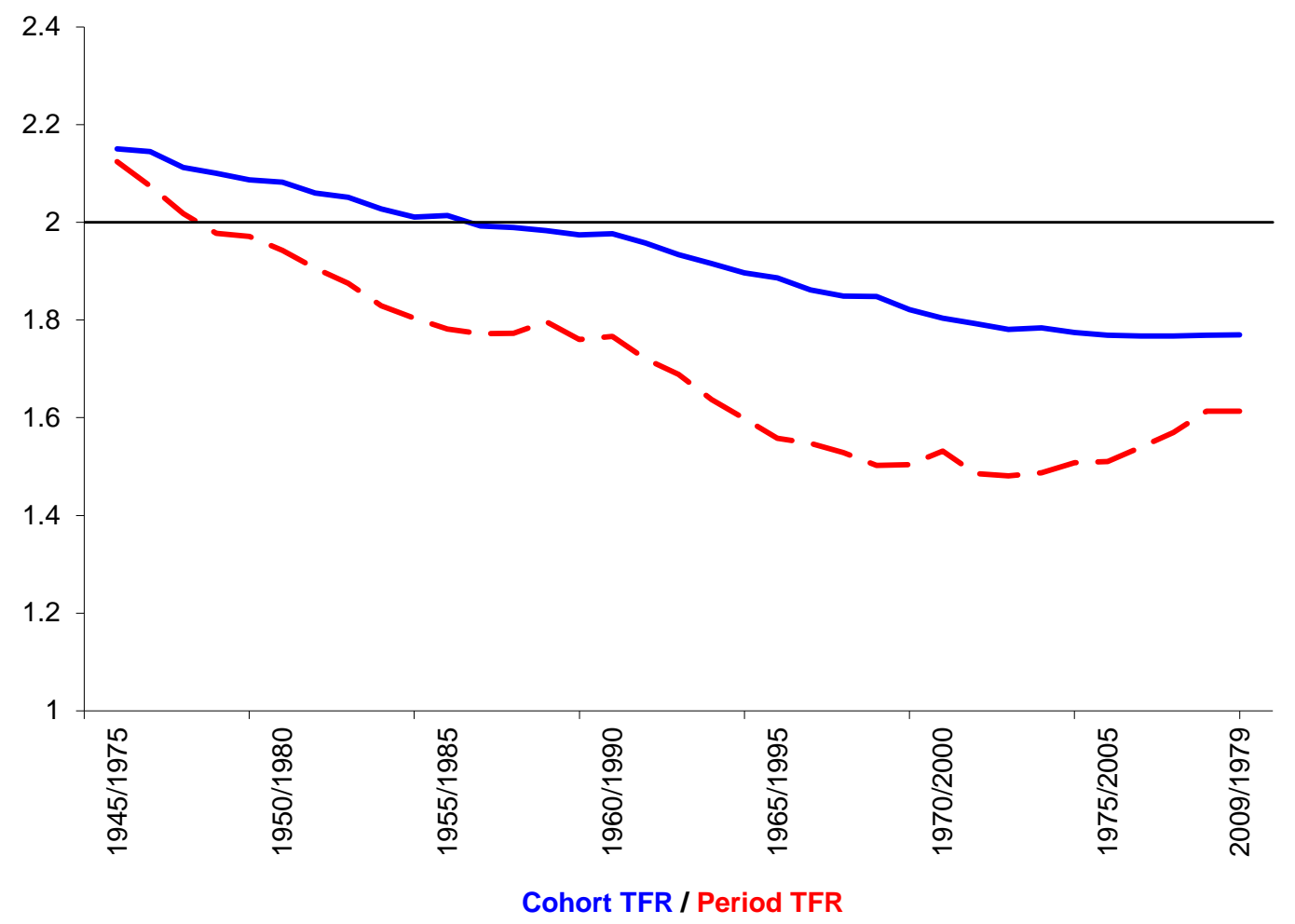

Countries included: Australia, Austria, Belgium, Bulgaria, Canada, Czech, Denmark, Estonia, Finland, France, Germany (East), Germany (West), Greece, Hungary, Iceland, Ireland, Italy, Japan, Korea, Lithuania, Luxembourg, Netherlands, New Zealand, Norway, Poland, Portugal, Romania, Russia, Singapore, Slovakia, Slovenia, Spain, Sweden, Switzerland, Taiwan, UK, USA 
Figure 2. Completed fertility for birth cohorts born between 1950 and 1979 by World Region. The thickest line in each panel shows the average fertility level of the region. The region averages are weighted by population size. The shaded region for birth cohorts 1975-79 highlights increasing uncertainty in the forecasts.
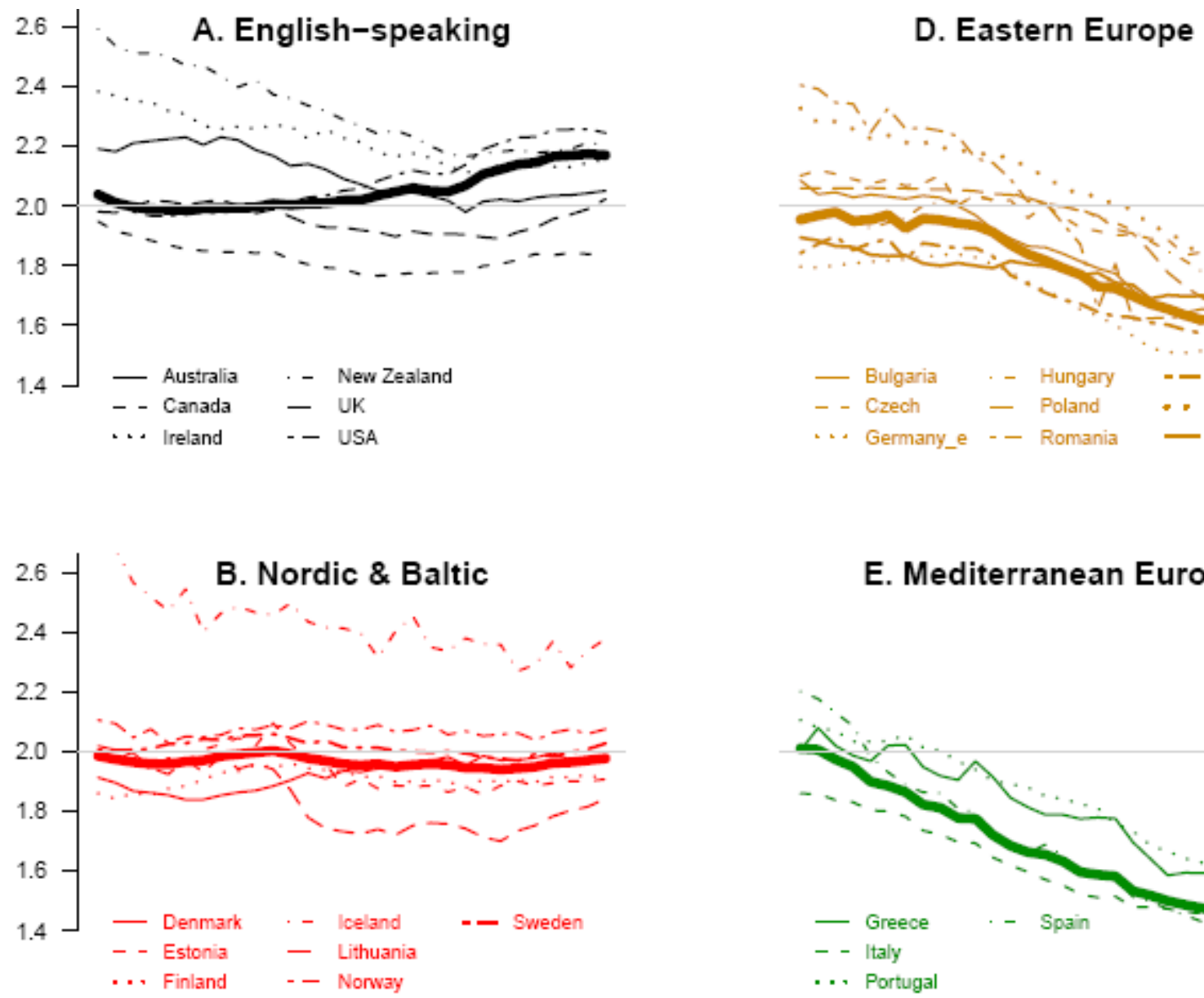

\section{E. Mediterranean Europe}
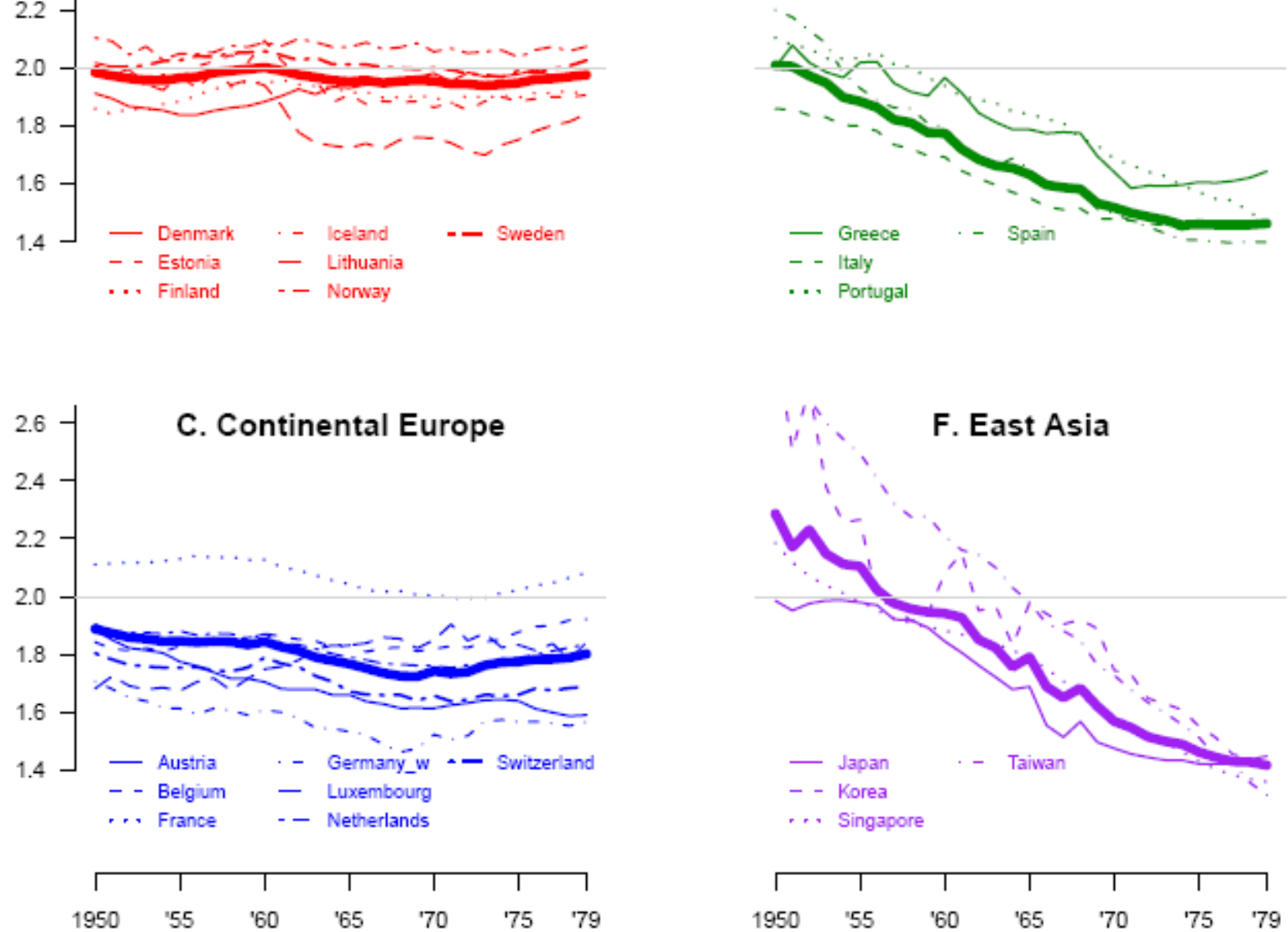

Birth cohorts 
Figure 3. Estimated completed cohort fertility levels in China. Calculations are based on period agespecific fertility data obtained from China Statistical Yearbook 1987-2010 (sample-based birth statistics) and Fertility Data Collection in China (for years prior to 1987) (National Bureau of Statistics of China. China Statistical Yearbook 1987-2010. (Beijing 1987-2010; Yao 1995)

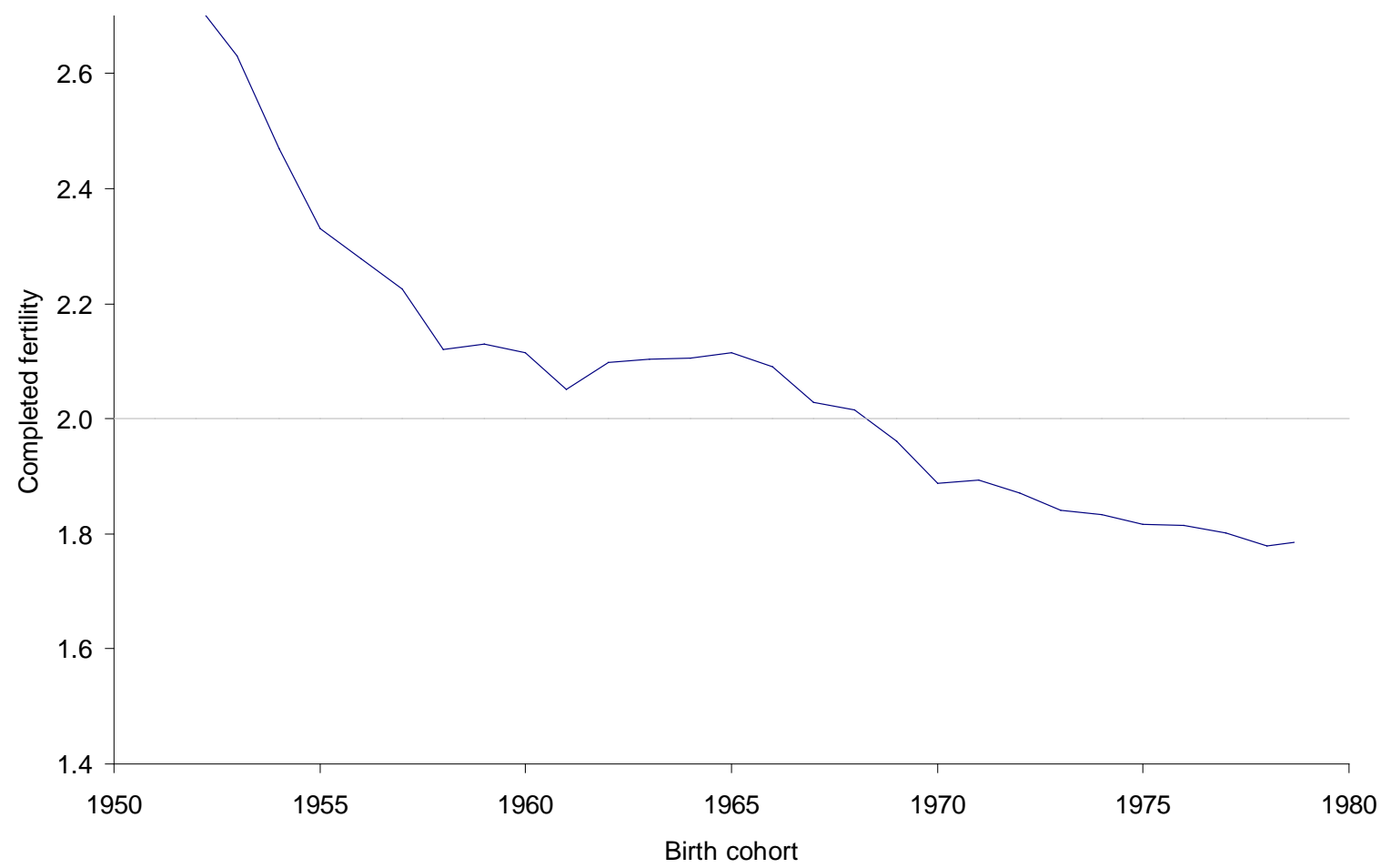


Figure 4. Forecasted cohort fertility rates and 95\% confidence interval for 6 selected countries.
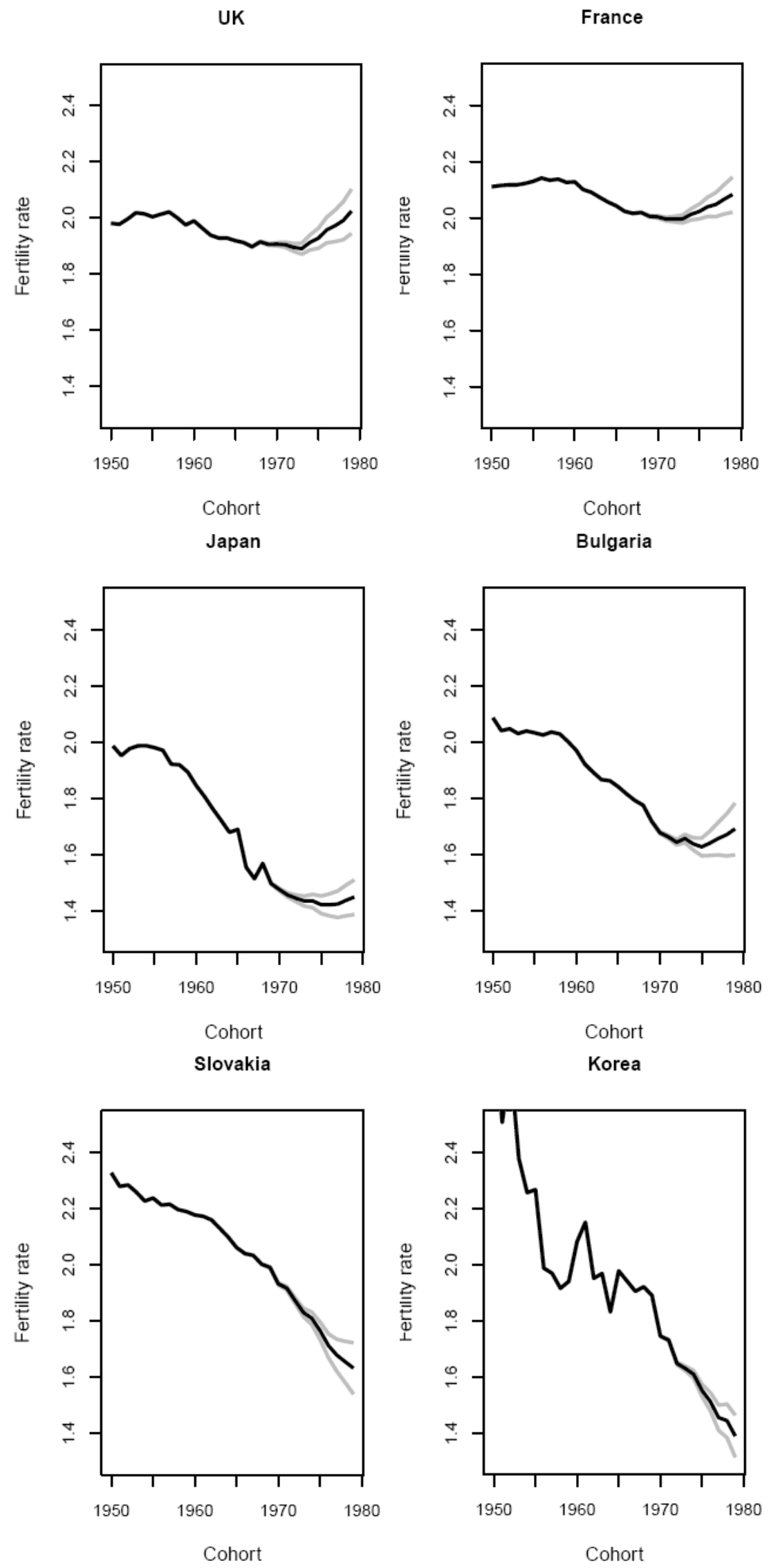
Figure 5. The association between the Global Gender Gap Index (GGG) in 2009 and completed Fertility for the 1979 cohorts in 35 countries. The GGG index combines equality in political participation, economic activity, health, and education. Only one observation is included for Germany (and no former East and West separately) because the GGG index is available only at the national level. The data sources and calculations are given in the Supporting Online Materials.

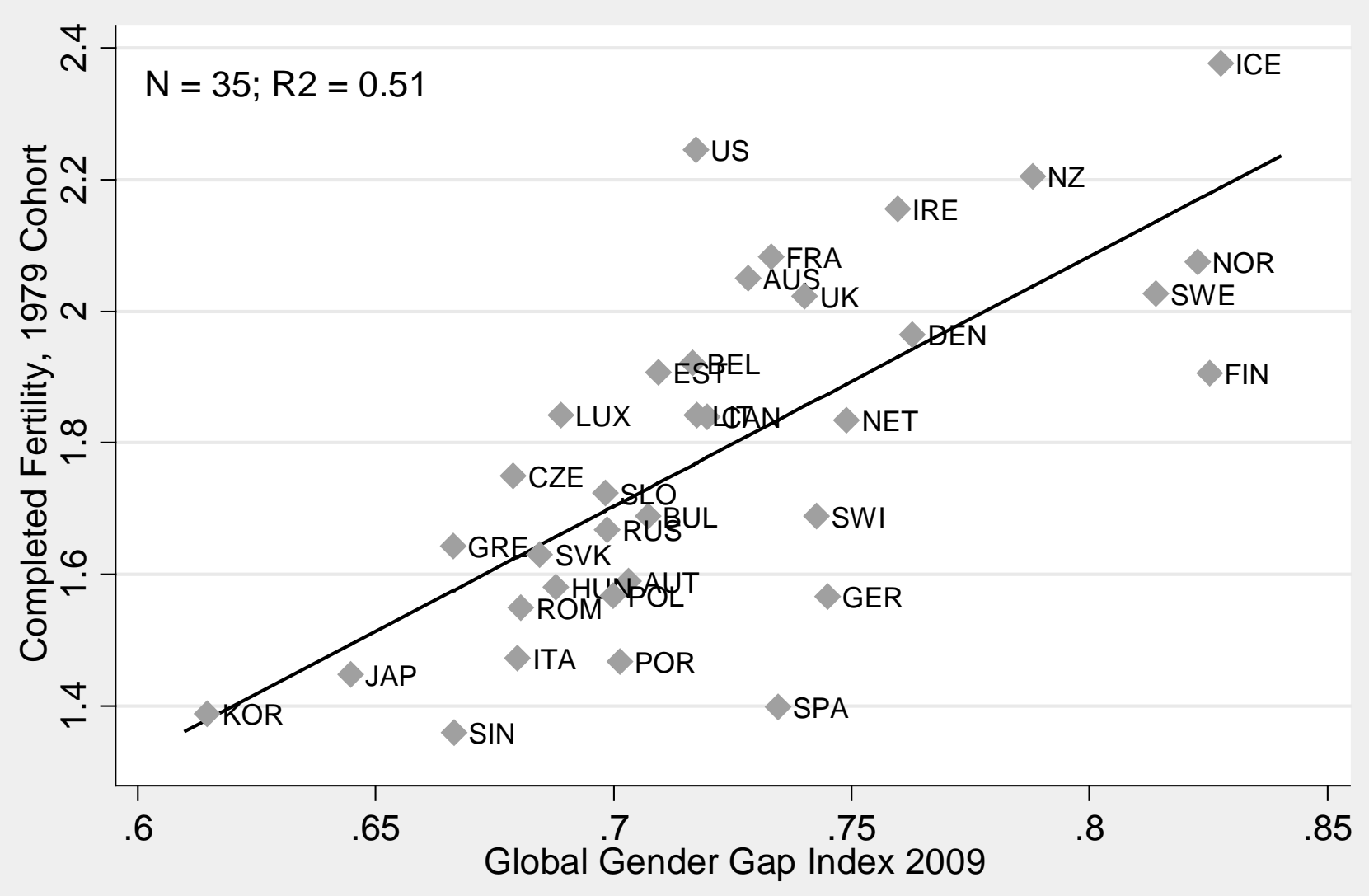


Table 1. List of countries and data sources.

\begin{tabular}{|c|c|c|c|}
\hline Country & Years & Source* & Notes** \\
\hline 1 Australia & 1965-2009 & Statistics Australia, www.abs.gov.au & 1965-1974 backcasted \\
\hline 2 Austria & 1965-2009 & Human Fertility Database & \\
\hline 3 Belgium & 1965-2009 & Eurostat & \\
\hline 4 Bulgaria & $1965-2009$ & Human Fertility Database & \\
\hline 5 Canada & $1965-2007$ & Human Fertility Database & \\
\hline 6 Czech & 1965-2009 & Human Fertility Database & \\
\hline 7 Denmark & 1965-2009 & Eurostat & \\
\hline 8 Estonia & 1965-2009 & Human Fertility Database & \\
\hline 9 Finland & 1965-2009 & Human Fertility Database & \\
\hline 10 France & 1965-2009 & Human Fertility Database & \\
\hline 11 Germany, East & 1965-2009 & Human Fertility Database & \\
\hline 12 Germany, West & 1965-2009 & Human Fertility Database & \\
\hline 13 Greece & 1965-2009 & Eurostat & \\
\hline 14 Hungary & 1965-2009 & Human Fertility Database & \\
\hline 15 Iceland & 1965-2009 & Eurostat & \\
\hline 16 Ireland & 1965-2009 & Human Fertility Database & \\
\hline 17 Italy & $1965-2009$ & Eurostat & \\
\hline 18 Japan & 1965-2009 & $\begin{array}{l}\text { Ryuichi Kaneko, Nat. Inst. of Population and Social Security } \\
\text { Research in Japan, and Rikiya Matsukura, Nihon University } \\
\text { Population Research Inst. in Japan. Personal communic. }\end{array}$ & . \\
\hline 19 Korea & 1965-2009 & $\begin{array}{l}\text { Kwang-Hee Jun, Professor of Demography and Sociology, } \\
\text { Chungnam National University. Personal communication }\end{array}$ & 1965-1969 backcasted \\
\hline 20 Lithuania & 1965-2009 & Human Fertility Database & \\
\hline 21 Luxembourg & 1965-2009 & Eurostat & 1965-1981 backcasted \\
\hline 22 Netherlands & 1965-2009 & Human Fertility Database & \\
\hline 23 New Zealand & 1965-2009 & Statistics New Zealand, www.stats.govt.nz & \\
\hline 24 Norway & 1965-2009 & Human Fertility Database up to $2006 ; 2007-2009$ Eurostat & \\
\hline 25 Poland & 1965-2009 & Eurostat & 1965-1989 backcasted \\
\hline 26 Portugal & 1965-2009 & Human Fertility Database & \\
\hline 27 Romania & 1965-2009 & Eurostat & 1965-1974 backcasted \\
\hline 28 Russia & 1965-2009 & Human Fertility Database & \\
\hline 29 Singapore & 1965-2009 & Population Trends 2010, Statistics Singapore & Data 5 year age intervals \\
\hline 30 Slovakia & 1965-2009 & Human Fertility Database & \\
\hline 31 Slovenia & 1965-2009 & Human Fertility Database & 1965-1982 backcasted \\
\hline 32 Spain & $1965-2006$ & Human Fertility Database up to 2006 ; 2007-2009 Eurostat & \\
\hline 33 Sweden & 1965-2009 & Human Fertility Database & \\
\hline 34 Switzerland & 1965-2009 & Human Fertility Database & \\
\hline 35 Taiwan & 1965-2009 & Statistical Yearbook of the Republic of China, 1976-2009 & 1965-1975 backcasted \\
\hline 36 UK & 1965-2009 & Human Fertility Database & 1965-1973 backcasted \\
\hline 37 USA & $1965-2007$ & Human Fertility Database & \\
\hline
\end{tabular}

* Human Fertility Database data are obtained from http://www.humanfertility.org/.

Eurostat data are obtained from http://epp.eurostat.ec.europa.eu/portal/page/portal/eurostat/home/

** For some countries, the data start later than in 1965. In such cases we backcasted the fertility rates to year 1965 by assuming that the rates that prevailed in the oldest observation year had been constant since 1965. 
Table 2. Cohort fertility and change in cohort fertility in 37 developed countries.

\begin{tabular}{|c|c|c|c|c|c|c|c|c|c|c|}
\hline & \multicolumn{5}{|c|}{ Fertility by birth cohort (CTFR) } & \multicolumn{4}{|c|}{$\begin{array}{l}\text { Change in CTFR; shaded } \\
\text { indicates decrease }\end{array}$} & \multirow{2}{*}{$\begin{array}{c}\text { Reversal } \\
\text { significant } \\
\left(^{\star}\right)\end{array}$} \\
\hline & 1950 & 1960 & 1970 & 1975 & 1979 & $\begin{array}{c}1950- \\
60 \\
\end{array}$ & $\begin{array}{c}1960- \\
70\end{array}$ & $\begin{array}{l}1970- \\
75\end{array}$ & $\begin{array}{c}1979- \\
75\end{array}$ & \\
\hline USA & 2.04 & 2.01 & 2.10 & 2.22 & 2.23 & -0.03 & 0.09 & 0.12 & 0.01 & * \\
\hline UK & 2.14 & 1.99 & 1.91 & 1.93 & 2.03 & -0.15 & -0.08 & 0.02 & 0.10 & * \\
\hline Lithuania & 2.02 & 1.94 & 1.76 & 1.76 & 1.86 & -0.08 & -0.18 & 0.00 & 0.10 & * \\
\hline Belgium & 1.84 & 1.87 & 1.82 & 1.88 & 1.91 & 0.03 & -0.05 & 0.06 & 0.04 & * \\
\hline Netherlands & 1.90 & 1.87 & 1.76 & 1.79 & 1.85 & -0.03 & -0.11 & 0.03 & 0.06 & * \\
\hline Russia & 1.84 & 1.86 & 1.61 & 1.62 & 1.69 & 0.02 & -0.25 & 0.01 & 0.07 & * \\
\hline $\begin{array}{l}\text { Germany, } \\
\text { East }\end{array}$ & 1.77 & 1.81 & 1.51 & 1.55 & 1.58 & 0.04 & -0.30 & 0.05 & 0.03 & * \\
\hline France & 2.11 & 2.13 & 2.00 & 2.02 & 2.08 & 0.02 & -0.12 & 0.02 & 0.06 & * \\
\hline Canada & 1.95 & 1.85 & 1.78 & 1.84 & 1.84 & -0.10 & -0.07 & 0.06 & 0.00 & \\
\hline $\begin{array}{l}\text { Germany, } \\
\text { West }\end{array}$ & 1.71 & 1.61 & 1.52 & 1.57 & 1.57 & -0.10 & -0.09 & 0.05 & 0.01 & * \\
\hline Iceland & 2.67 & 2.46 & 2.34 & 2.31 & 2.39 & -0.21 & -0.12 & -0.03 & 0.09 & * \\
\hline Slovenia & 2.14 & 1.84 & 1.69 & 1.70 & 1.73 & -0.30 & -0.15 & 0.01 & 0.03 & \\
\hline Estonia & 1.99 & 2.09 & 1.86 & 1.89 & 1.90 & 0.10 & -0.23 & 0.02 & 0.02 & \\
\hline Ireland & 3.08 & 2.37 & 2.13 & 2.14 & 2.17 & -0.71 & -0.24 & 0.01 & 0.03 & \\
\hline N. Zealand & 2.59 & 2.37 & 2.17 & 2.18 & 2.21 & -0.22 & -0.20 & 0.00 & 0.03 & \\
\hline Switzerland & 1.80 & 1.79 & 1.66 & 1.66 & 1.69 & -0.01 & -0.13 & 0.00 & 0.03 & \\
\hline Norway & 2.10 & 2.09 & 2.06 & 2.04 & 2.09 & -0.02 & -0.03 & -0.01 & 0.05 & \\
\hline Sweden & 2.00 & 2.06 & 2.00 & 2.00 & 2.03 & 0.05 & -0.06 & -0.01 & 0.04 & \\
\hline Australia & 2.42 & 2.17 & 2.02 & 2.03 & 2.05 & -0.25 & -0.15 & 0.01 & 0.02 & \\
\hline Bulgaria & 2.09 & 1.97 & 1.68 & 1.63 & 1.70 & -0.12 & -0.29 & -0.05 & 0.07 & \\
\hline Finland & 1.86 & 1.95 & 1.90 & 1.90 & 1.92 & 0.09 & -0.05 & 0.00 & 0.02 & * \\
\hline Italy & 1.86 & 1.69 & 1.48 & 1.46 & 1.49 & -0.17 & -0.21 & -0.02 & 0.03 & \\
\hline Greece & 2.00 & 1.97 & 1.64 & 1.61 & 1.65 & -0.04 & -0.32 & -0.03 & 0.04 & \\
\hline Luxembourg & 1.70 & 1.75 & 1.85 & 1.84 & 1.85 & 0.05 & 0.10 & -0.01 & 0.02 & * \\
\hline Japan & 1.99 & 1.85 & 1.48 & 1.43 & 1.47 & -0.14 & -0.37 & -0.05 & 0.04 & \\
\hline Denmark & 1.91 & 1.88 & 1.98 & 1.98 & 1.96 & -0.03 & 0.10 & 0.00 & -0.02 & \\
\hline Austria & 1.89 & 1.70 & 1.61 & 1.64 & 1.59 & -0.18 & -0.09 & 0.03 & -0.05 & \\
\hline Romania & 2.52 & 2.16 & 1.62 & 1.56 & 1.54 & -0.36 & -0.54 & -0.06 & -0.02 & \\
\hline Spain & 2.20 & 1.80 & 1.50 & 1.41 & 1.40 & -0.40 & -0.30 & -0.09 & -0.01 & \\
\hline Czech & 2.10 & 2.04 & 1.89 & 1.81 & 1.75 & -0.06 & -0.15 & -0.08 & -0.06 & \\
\hline Singapore & 2.19 & 1.88 & 1.59 & 1.43 & 1.36 & -0.30 & -0.29 & -0.15 & -0.07 & \\
\hline Portugal & 2.11 & 1.94 & 1.69 & 1.57 & 1.46 & -0.17 & -0.25 & -0.11 & -0.11 & \\
\hline Poland & 2.25 & 2.22 & 1.85 & 1.64 & 1.57 & -0.04 & -0.36 & -0.22 & -0.06 & \\
\hline Slovakia & 2.33 & 2.18 & 1.93 & 1.77 & 1.64 & -0.15 & -0.24 & -0.16 & -0.13 & \\
\hline Hungary & 1.97 & 2.03 & 1.88 & 1.68 & 1.57 & 0.06 & -0.15 & -0.20 & -0.11 & \\
\hline Korea & 2.90 & 2.08 & 1.75 & 1.56 & 1.41 & -0.82 & -0.34 & -0.19 & -0.15 & \\
\hline Taiwan & 2.86 & 2.20 & 1.74 & 1.55 & 1.35 & -0.66 & -0.47 & -0.19 & -0.19 & \\
\hline Average & 2.13 & 1.99 & 1.80 & 1.77 & 1.77 & -0.14 & -0.19 & -0.03 & 0.00 & \\
\hline Median & & & & & & -0.10 & -0.15 & 0.00 & 0.02 & \\
\hline \multicolumn{6}{|c|}{ \# countries stable or increasing } & 9 & 3 & 19 & 25 & \\
\hline \multicolumn{6}{|c|}{ \# countries with significant increase } & & & & & 12 \\
\hline
\end{tabular}

Note: Countries ranked based on the change in CTFR over the 1970-1979 birth cohorts.

*Reversal significant if the lower bound of the 95\% confidence interval for the 1979 cohort is above the lowest CTFR across the 1960-1975 cohorts. 
Table 3. Forecast uncertainty summarized in terms of CI length.

\begin{tabular}{lcccccccc}
\hline & $\begin{array}{c}\text { Birth } \\
\text { cohort } \\
\end{array}$ \\
& 1950 & 1960 & 1970 & 1975 & 1976 & 1977 & 1978 & 1979 \\
\hline $\begin{array}{l}\text { Average Cl width } \\
\begin{array}{l}\text { Ratio of the Cl width to } \\
\text { total forecasted TFR }\end{array}\end{array}$ & 0 & 0 & 0.01 & 0.06 & 0.08 & 0.10 & 0.12 & 0.14 \\
$\begin{array}{l}\text { Ratio of the Cl width to } \\
\text { the forecasted part ofTFR }\end{array}$ & - & - & 0.01 & 0.04 & 0.05 & 0.06 & 0.07 & 0.08 \\
\hline
\end{tabular}


TABLE 4 Simulated impact of the late 2000 s recession on cohort total fertility rates (CTFR) for the 1970 s birth cohorts

\begin{tabular}{|c|c|c|c|c|c|c|}
\hline & \multirow{3}{*}{$\begin{array}{l}\text { Average } \\
\text { CTFR, } \\
1979 \\
\text { cohort }\end{array}$} & \multirow{3}{*}{$\begin{array}{l}\text { No. of } \\
\text { countrles } \\
\text { with } 1979 \\
\text { CTFR }>1.75\end{array}$} & \multicolumn{4}{|c|}{$\begin{array}{l}\text { Number of countries experlencing } \\
\text { spectified CTFR change over the }\end{array}$} \\
\hline & & & \multicolumn{2}{|c|}{$1975-79$ cohorts } & \multicolumn{2}{|c|}{$1970-79$ cohorts } \\
\hline & & & $\begin{array}{l}\text { Change } \\
=0\end{array}$ & $\begin{array}{l}\text { Change } \\
<0\end{array}$ & $\begin{array}{l}\text { Change } \\
=0\end{array}$ & $\begin{array}{l}\text { Change } \\
<0\end{array}$ \\
\hline $\begin{array}{l}\text { Baseline forecast using data } \\
\text { up to } 2009\end{array}$ & 1.77 & 18 & 22 & 15 & 24 & 13 \\
\hline \multicolumn{7}{|l|}{ 2008-09 change multiplied } \\
\hline by factor of 2 & 1.76 & 18 & 25 & 12 & 21 & 16 \\
\hline by factor of 3 & 1.75 & 17 & 22 & 15 & 18 & 19 \\
\hline by factor of 4 & 1.73 & 16 & 19 & 18 & 14 & 23 \\
\hline \multicolumn{7}{|l|}{ 2008-10 change multiplied } \\
\hline by factor of 2 & 1.75 & 18 & 24 & 13 & 20 & 17 \\
\hline by factor of 3 & 1.74 & 17 & 21 & 16 & 16 & 21 \\
\hline by factor of 4 & 1.72 & 16 & 20 & 17 & 15 & 22 \\
\hline
\end{tabular}

NOTE: Based on a total of 37 countrics. 
Table 5. Characteristics of the European Population in 2000-2300 by fertility and migration levels. The population projection is based on the EU 27 population in 2000. The fertility schedules are based on the EU 27 average in 2003 and rescaled to either a TFR of 1.5 or 1.75. Mortality is assumed to follow the United Nations long term projection for life expectancy for Europe. Migration is set to either zero, or to a level that offsets the effect of low fertility so that the population growth rate is zero.

\begin{tabular}{|c|c|c|c|c|}
\hline Year & $\begin{array}{c}\text { TFR 1.5, } \\
\text { no migration }\end{array}$ & $\begin{array}{c}\text { TFR 1.5, } \\
\text { replacement } \\
\text { migration }\end{array}$ & $\begin{array}{c}\text { TFR } 1.75, \\
\text { no migration }\end{array}$ & $\begin{array}{c}\text { TFR 1.75, } \\
\text { replacement } \\
\text { migration }\end{array}$ \\
\hline \multicolumn{5}{|c|}{ Population } \\
\hline 2000 & 482.8 & 482.8 & 482.8 & 482.8 \\
\hline 2050 & 377.8 & 482.8 & 424.1 & 483.2 \\
\hline 2100 & 241.2 & 482.8 & 343.1 & 483.2 \\
\hline 2200 & 93.6 & 482.8 & 220.8 & 483.2 \\
\hline 2300 & 35.0 & 482.8 & 137.7 & 483.2 \\
\hline \multicolumn{5}{|l|}{ Mean Age } \\
\hline 2000 & 39.25 & 39.25 & 39.25 & 39.25 \\
\hline 2050 & 47.50 & 44.09 & 44.77 & 42.95 \\
\hline 2100 & 50.83 & 46.52 & 47.29 & 45.47 \\
\hline 2200 & 55.75 & 50.27 & 51.72 & 49.15 \\
\hline 2300 & 59.59 & 53.13 & 55.16 & 52.04 \\
\hline \multicolumn{5}{|c|}{ Old Age Support Ratio: Population aged 15-64 divided by population aged $65+$} \\
\hline 2000 & 4.31 & 4.31 & 4.31 & 4.31 \\
\hline 2050 & 2.06 & 2.69 & 2.33 & 2.71 \\
\hline 2100 & 1.56 & 2.17 & 1.90 & 2.17 \\
\hline 2200 & 1.10 & 1.60 & 1.36 & 1.62 \\
\hline 2300 & 0.88 & 1.34 & 1.11 & 1.35 \\
\hline \multicolumn{5}{|c|}{ Ratio of migrants to newborns } \\
\hline \multicolumn{5}{|l|}{2000} \\
\hline 2050 & & & 0.361 & 0.188 \\
\hline 2100 & & & 0.334 & 0.147 \\
\hline 2200 & & & 0.354 & 0.158 \\
\hline 2300 & & & 0.359 & 0.160 \\
\hline
\end{tabular}


Table 6. Regression of completed fertility for the 1979 cohort on GGG, GDP, and HDI for the year 2009. The list of countries used in the regressions is given in Table 1. Note: The regressions include only one Germany, not separately former East and West.

\begin{tabular}{lcccc}
\hline & Model 1 & Model 2 & Model 3 & Model 4 \\
\hline $\mathrm{N}$ & 35 & 35 & 35 & 35 \\
$\mathrm{R} 2$ & 0.51 & 0.10 & 0.18 & 0.53 \\
Constant & -0.96 & -0.43 & -0.36 & -1.34 \\
Gender equality GGG & $3.80^{\star \star \star}$ & & & $3.44^{\star \star \star}$ \\
Log of GDP/capita & & $0.07^{\wedge} \mathrm{t}$ & & -0.03 \\
Human Development Index HDI & & $2.47^{\star \star}$ & 1.15 \\
\hline
\end{tabular}

$* \mathrm{p}<.05 * * \mathrm{p}<.01 * * * \mathrm{p}<.001$

Notes: Model 1 examines the relationship between cohort fertility and gender equality. Model 2 estimates the association between cohort fertility and GDP. Model 3 looks at the relationship between cohort fertility and HDI. Model 4 includes all three indices of gender equality, GDP and HDI as predictors of cohort fertility. 


\section{Appendix. Forecast accuracy for alternative extrapolation methods}

We studied the forecast accuracy of the 5-year extrapolation method using historical data and compared the performance to alternative extrapolation methods: the freeze rates method, which assumes that agespecific fertility rates stay at the last observed level, and unlimited extrapolation, which assumes that observed trends continue uninterrupted into the future.

We test the three methods with completed cohort data. We let the methods use the data only up to certain age, forecast completed cohort fertility with this limited data, and compare the results to the known completed fertility. In the comparison we use data for twenty three countries and cohorts 1950-1965: Austria (1951-2009), Belgium (1961-2009), Bulgaria (1961-2009), Canada (1950-2007), Czech Republic (1950-2009), Denmark (1960-2009), Estonia (1959-2009), Finland (1950-2009), France (1950-2009), Greece (1961-2009), Hungary (1961-2009), Italy (1960-2009), Japan (1950-2009), the Netherlands (1950-2009), Norway (1961-2009), Portugal (1960-2009), Russia (1959-2009), Slovakia (1950-2009), Spain (1971-2009), Sweden (1950-2009), Switzerland (1950-2009), the United States (1950-2007), and West Germany (1952-2009).

All data obtained are organised in a format of age by period fertility matrix. There are 35 ages (from ages 15/16 to 49/50) for every year of observation. Cohort fertility schedules are obtained by taking the diagonal values of these period matrices. In the case where both period and cohort schedules are available for all HFD countries, the authors tried to estimate the differences in CTFR by using diagonal rates from a period fertility matrix versus by using real cohort schedules. The differences are minimal, normally in the range of 0.01 of a birth or smaller.

For each completed cohort, sixteen observed schedules were generated by truncating the data between the ages 30 to 45. The three methods were then applied to these schedules to estimate completed cohort total fertility rate CTFR. This procedure is repeated for the cohorts born from 1950 to 1965 . Forecast errors 
were calculated by taking the difference between the forecasted CTFR level (at different truncation ages) and the actual observed CTFR. For cohorts who have not completed but are close to the end of their reproductive careers (e.g. cohorts born between 1958 and 1965, assuming age 50 is the “end” of reproduction), we used the forecasted CTFR obtained by linear extrapolation with fixed trend as the final “completed” fertility level. The difference between completed fertility at age 43 (for the 1965 cohort) and the forecast that uses forecasted fertility at age 44 and above is small for all countries.

Appendix Figure A.2 illustrates the forecasts accuracy for Danish, Austrian, Japanese, and Italian 1960 birth cohorts. For most countries and truncation ages, the frozen rate method underestimates cohort fertility. Linear extrapolation methods, both with fixed trend and limited 5 year extrapolation, tend to forecast cohort fertility more accurately. In particular, the downward bias seems smaller than it is for the frozen rates method. For all methods the estimated CTFR level approaches the real CTFR when truncation age increases.

Appendix Figure A.3 shows summary statistics for the accuracy of the three methods. Here we have calculated the forecast errors for each country and cohort by forecasting method and truncation age. For each forecasting method and truncation age, there are $22 \cdot 16+10=362$ error observations (22 countries multiplied by 16 truncated cohorts plus 10 cohorts for Spain due to shorter data length). From this set of errors we have calculated the forecast bias as the average of forecast errors (bias, Panel A) and root mean square error of forecasts (RMSE, Panel B).

The forecasts are systematically downward biased, underestimating cohort fertility at all truncation ages below 40 (Panel A). The bias, however, is markedly smaller for linear extrapolation methods than for the frozen rates method. As the bias is downward, our forecasts of cohort fertility may be conservative in particular for the youngest cohorts. For all method the bias decreases rapidly with truncation age. For our preferred five year extrapolation the bias is -0.029 (alternatively, $1 / 33^{\text {rd }}$ of a child or $1.6 \%$ of the ultimate 
cohort fertility) at truncation age 30, which corresponds to the 1979 cohort in most countries since the data is used up to year 2009. At ages 33 and above (which corresponds to the 1975 and earlier cohorts) the bias is less than $1 / 75^{\text {th }}$ of a child.

The ultimate measure of accuracy (RMSE) combines bias and variation and describes in a single figure the accuracy of the method. As shown in Panel B, the 5-year extrapolation method performs best in terms of RMSE. At all truncation ages, RMSE is smaller for limited linear extrapolation than for the other two methods. Frozen rates method, in turn, is consistently at all truncation ages the least accurate. For our preferred 5-year extrapolation method, RMSE suggests that at truncation age 33 the average forecasting error is less than 0.02 , or less than $1 / 50^{\text {th }}$ of a child. In relation to the ultimate completed fertility, this is less than 1 percentage point.

These results show that the limited extrapolation markedly improves the forecast accuracy and reduces the underestimation of previous research which predicted lifetime fertility for the 1975 cohorts to be as low as 1.2-1.3 children per woman in several European countries (Frejka and Calot 2001; Frejka and Sardon 2004). According to the forecast error evaluation, we suggest that the forecasted CTFR values obtained from the frozen-rate method are consistently inaccurate. As shown in our experiments, frozen rates method systematically underestimates completed cohort fertility levels. Linear extrapolation, either with a fixed trend or lasting for five years, consistently outperforms the frozen rates method. Of the two extrapolation methods, the limited linear extrapolation performs better than the eternal extrapolation, and is the method used in the following analysis.

We also studied the sensitivity of our results by using a longer or shorter window from which to estimate the past trend. We experimented with 3 years, 5 years, and 10 years. Judged against historical data, the trend observed over the last five years resulted in best forecast accuracy (results not shown). 
APPENDIX FIGURE 1 Forecasted cohort fertility rates and simulated 95 percent confidence interval for 37 countries

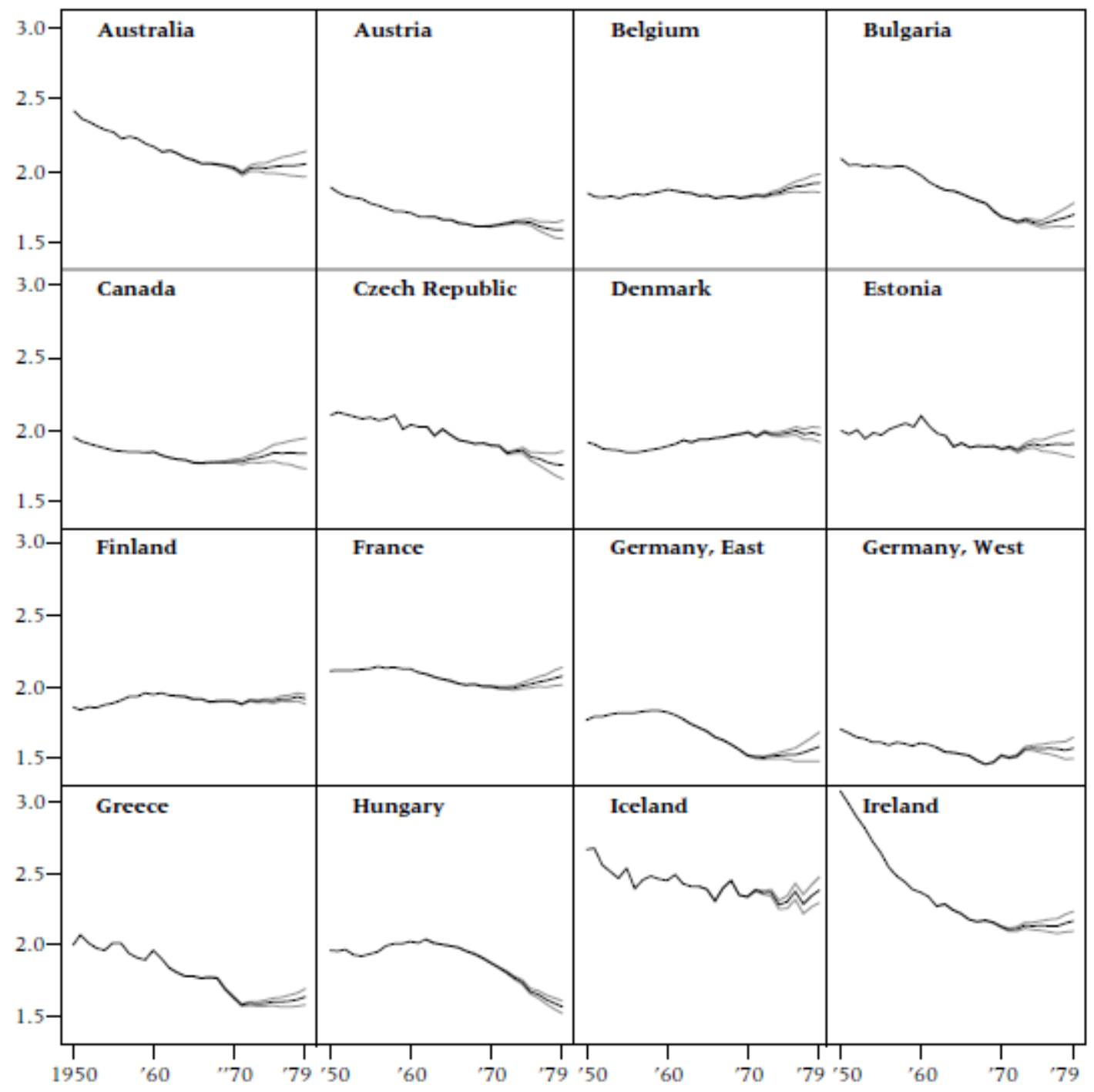


APPENDIX FIGURE 1 (continued)

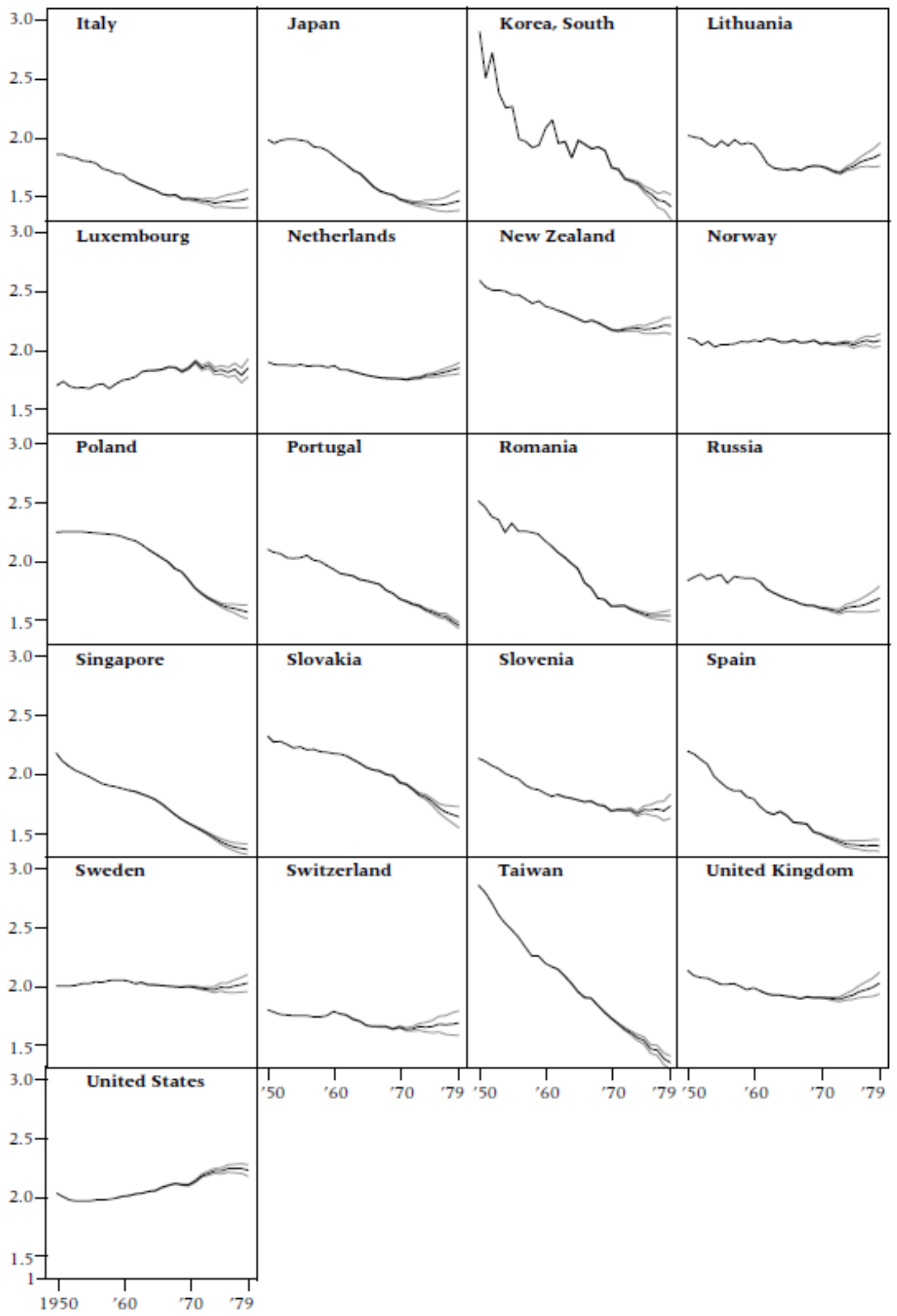

NOTE: See methods section of text for details of the simulation. 
Appendix Figure A.2. Forecasted cohort total fertility rate (CTFR) vs. Observed CTFR for selected 1960 cohorts by age at which the forecast starts (Truncation Age).
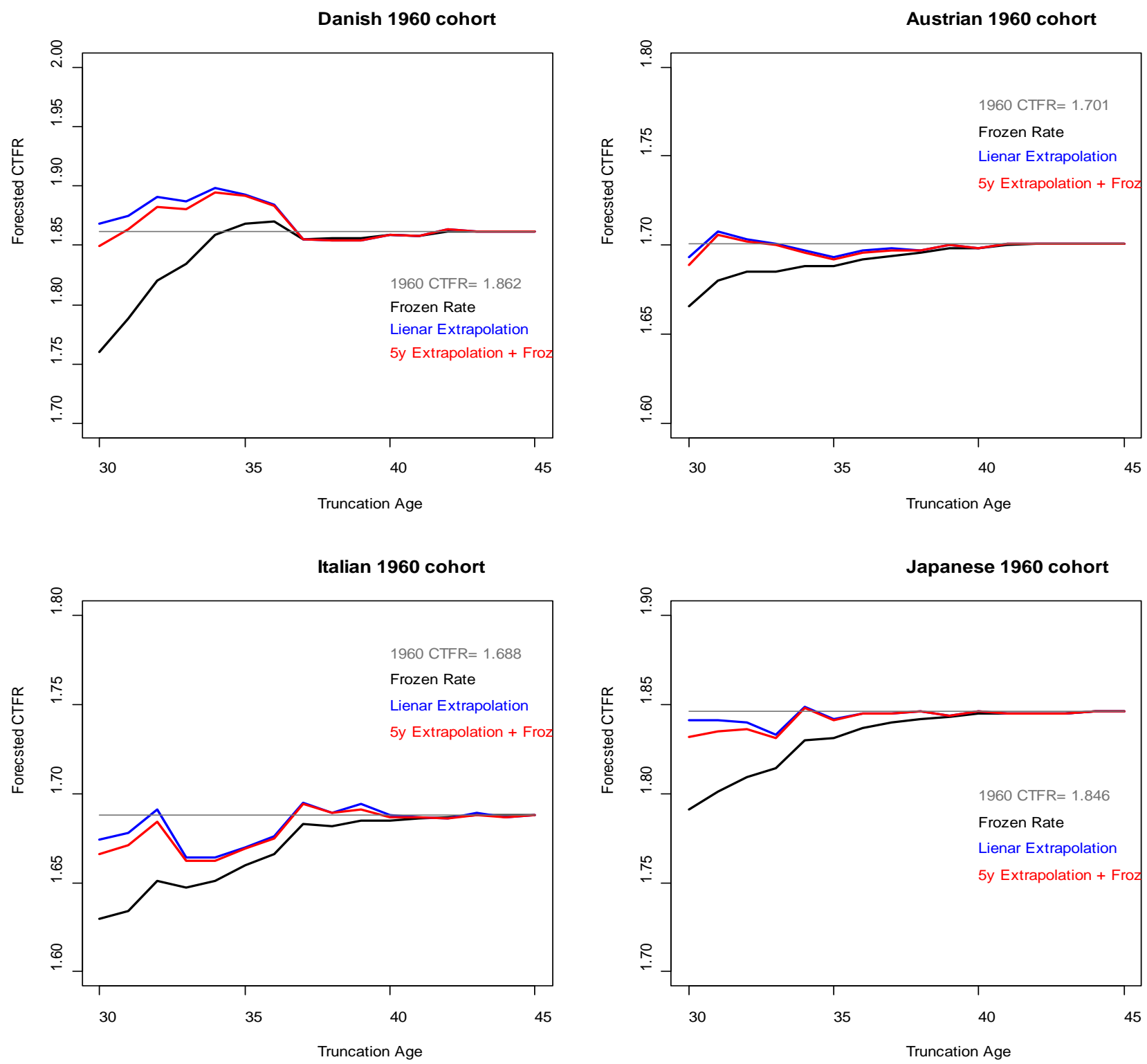
Appendix Figure A.3.Mean Bias and Root Mean Square Error of Forecasts by Forecasting Method and Truncation Age. The accuracy of each forecasting method is evaluated using out-of-sample forecast errors for 23 countries and 1950-1965 cohorts.
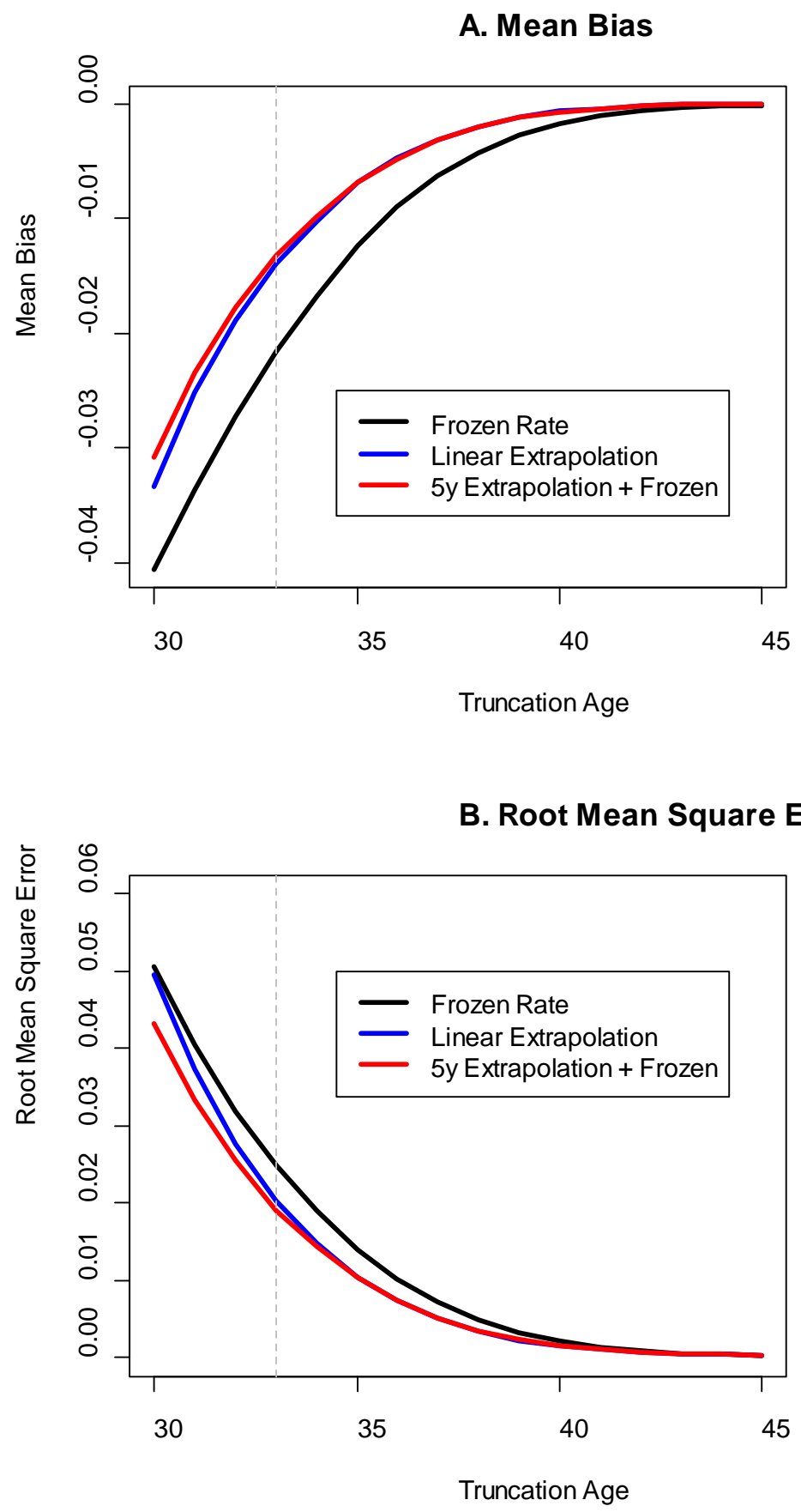


\section{Endnotes}

${ }^{1}$ In the linear extrapolation with fixed trend, we force the rates to 0.001 in the rare occasions where they drop below zero. In the new 5 year extrapolation method we did not observe negative rates.

${ }^{2}$ Our evaluation of the forecast errors is based on the 1950-1965 cohorts. Historical errors may over- or underestimate the uncertainty for current cohorts. Due to postponement of fertility current cohorts have on average achieved less of their ultimate fertility for any fixed age than the earlier cohorts. This may reduce the accuracy of the forecasts for the current cohorts when compared to historical performance. On the other hand, forecast uncertainty may be lower for the 1970s cohorts than for the 1950s-1960s cohorts because the period fertility trend shows that in many low fertility countries women aged 30 or above have experienced gradual and steady fertility recuperation since the early 1980s. Such pattern appeared roughly a decade later in Southern and Eastern European countries. This inflection in the trend has contributed to more accurate extrapolation-based forecasts for more recent cohorts, particularly those born in the 1970s. For earlier cohorts, forecast errors tend to be negatively larger because extrapolated rates were obtained from a downward-going trend before the inflection point.

${ }^{3}$ We also considered using the 1970 and 1975 birth cohorts, for which the forecast uncertainty is markedly lower than for the 1979 birth cohort. The results were very similar for the 1970, 1975 and 1979 birth cohorts.

${ }^{4} \mathrm{HDI}$ is based on 3 components, of which one is GDP. Therefore HDI and GDP are highly correlated, and the high correlation could attenuate the predictive power of one or the other variable in a model including GGG, HDI, and GDP. Therefore we estimated two additional models, one in which cohort fertility was regressed on GGG and HDI, another on GGG and GDP. The results were similar to what was observed with a regression where GGG, GDP and HDI are all included. 